\title{
MASTER
}

\section{ACES Demonstration: Construction, Startup, and Performance Report}

\author{
A. S. Holman \\ V. R. Brantley
}

OAK RIDGE NATIONAL LABORATORY OPERATED BY UNION CARBIDE CORPORATION · FOR THE DEPARTMENT OF ENERGY 


\section{DISCLAIMER}

This report was prepared as an account of work sponsored by an agency of the United States Government. Neither the United States Government nor any agency Thereof, nor any of their employees, makes any warranty, express or implied, or assumes any legal liability or responsibility for the accuracy, completeness, or usefulness of any information, apparatus, product, or process disclosed, or represents that its use would not infringe privately owned rights. Reference herein to any specific commercial product, process, or service by trade name, trademark, manufacturer, or otherwise does not necessarily constitute or imply its endorsement, recommendation, or favoring by the United States Government or any agency thereof. The views and opinions of authors expressed herein do not necessarily state or reflect those of the United States Government or any agency thereof. 


\section{DISCLAIMER}

Portions of this document may be illegible in electronic image products. Images are produced from the best available original document. 
Printed in the United States of America. Available from National Technical Information Service

U.S. Department of Commerce

5285 Port Royal Road, Springfield, Virginia 22161

Price: Printed Copy $\$ 6.00$; Microfiche $\$ 3.00$

This report was prepared as an account of work sponsored by an agency of the United States Government. Neither the United States Government nor any agency thereof, nor any of their employees, contractors, subcontractors, or their employees, makes any warranty, express or implied, nor assumes any legal liability or responsibility for any third party's use or the results of such use of any information, apparatus, product or process disclosed in this report, nor represents that its use by such third party would not infringe privately owned rights. 
Contract No. W-7405-eng-26

ENERGY DIVISION

ACES DEMONSTRATION: CONSTRUCTION, STARTUP, AND PERFORMANCE REPORT

A. S. Holman

V. R. Brantley

Department of Energy

Division of Buildings and Community Systems

Date Fublished: October 1978

ONK RIDGE NATIONAL LABORATORY

Oak Ridge, 'l'ennessee 37830

operated by

UNION CARBIDE CORPORATION

for the

DEPARTMENT OF ENERGY 


\section{THIS PAGE \\ WAS INTENTIONALLY \\ LEFT BLANK}


CONTENTS

ABSTRACT . . . . . . . . . . . . . . . . . . . . . . . . . 1

1. SUMMARY . . . . . . . . . . . . . . . . . . . . . . 1

2. PROJECT DESCRIPTION . . . . . . . . . . . . . . . . . . 5

2.1 The House . . . . . . . . . . . . . . . . . . . . . 5

2.1.1 Architectural ................. 5

2.1.2 Thermal envelope . . . . . . . . . . . . . . . . 5

2.1 .3 Building loads . . . . . . . . . . . . . 10

2.2 The ACES ... . . . . . . . . . . . . . . . . 14

2.2.1 The $\Lambda$ CES concept . . . . . . . . . . ..... . 14

2.2.2 ACES modes of operation . . . . . . . . . . . 15

2.2.3 ACES features . . . . . . . . . . . . 22

3. CONSTRUCTION, INSTALLATION, AND OPERATIONAL EXPERIENCE . . . . . 25

3.1 House Construction . . . . . . . . . . . . . . . . . . . . 25

3.1.1 Thermal storage bin walls . . . . . . . . . . 25

3.1.2 Exterior wall framing . . . . . . . . . . . . 30

3.1.3 Ceiling . . . . . . . . . . . . . . . . 31

3.2 ACES Installation . . . . . . . . . . . . . . . . . 31

3.2.1 Ice-and-water storage bin ... . . . . . . . . . . . 31

3.2.2 ACES mechanical package . . . . . . . ... . . . 34

3.3 ACES Operation . . . . . . . . . . . . . . . . . . . . . . 35

3.3.1 Initial operating experiences . . . . . . . . . . 35

3.3.2 Fine tuning the ACES . . . . . . . . . . . . . . . . 36

3.4 ACES Startup .. . . . . . . . . . . . . . . . 36

3.4.1 Corrosion problems . . . . . . . . . . . . . . . . . 36

3.4.2 Thermal storage bin problems . . . . . . . . . . . 37

3.4.3 Mechanical package problems . . . . . . . . . . 38

4. NEW MECHANICAL PACKAGE . . . . . . . . . . . . . . . . . . . . . 39

4.1 Package Design . . . . . . . . . . . . . . . . . . . 39

4.2 Installation and Startup . . . . . . . . . . . . . 41

5. ACES PERFORMANCE . . . . . . . . . . . . . . . . . . . . . . 43

5.1 Steady-State Performance . . . . . . . . . . . . . . 43

5.2 Winter Performance . . . . . . . . . . . . . . . . 44

5.2.1 Winter energy usage . . . . . . . . . . . . . . . . 44

5.2.2 Winter load profile . . . . . . . . . . . . . 47

5.2 .3 Winter bin performance . . . . . . . . . . . . . 48

5.3. Summer Performance . . . . . . . . . . . . . . . . . 51

5.3.1 Summer energy usage . . . . . . . . . . . . . . 51

5.3.2 Summer load management . . . . . . . . . . . . . 51

Appendix A. COMPONENT SPECIFICATIONS AND DESIGN DATA . . . . . . 55

Append1X B. MECHANICAL PACKAGE DESIGN SPECIFICAIIONS . . • . • . . 61

REFERENCES . . . . . . . . . . . . . . . . . . . . 75 
THIS PAGE

\section{WAS INTENTIONALLY LEFT BLANK}




\section{LIST OF FIGURES}

2.1 Basement plan .................. 6

2.2 First floor plan ................. 7

2.3 Second floor plan ................ . 8

2.4 Artist's conception of ACES house . . . . . . . . . . 9

2.5 Space heating schematic............. . 16

2.6 Hot water schematic . . . . . . . . . . . 18

2.7 Space cooling schematic.............. 19

2.8 Ice melt schematic . . . . . . . . . . . 20

2.9 Night heat rejection schematic . . . . . . . . . 21

3.1 Foam Form . . . . . . . . . . . . . . 26

3.2 Styrofoam forms at ACES house . . . . . . . . . . 27

3.3 Looking south at ACES house . . . . . . . . . . 28

3.4 Four courses of styrofoam forms in place at ACES

3.5 Original ice-freezing coils... . . . . . . . 32

3.6 Original ice-freezing coils installed . . . . . . . 33

4.1 Refrigerant and brine schematic . . . . . . . . . 40

4.2 COP as a function of refrigerant charge . . . . . . . 42

Evaporator temperature as a function of ice on the
tubing . . . . . . . . . . . . . . . . . 45

5.2 ACES performance analysis, week beginning January 2,
1978 . . . . . . . . . . . . . . . . 46

5.3 Comparison of ACES and control houses, week beginning January 2, 1978 . . . . . . . . . . . . . . 49

5.4 Ice inventory as a function of time . . . . . . . . 50

5.5 Comparison of ACES and control houses, week beginning August 1, 1977 . . . . . . . . . . . . . . . 52 

A. 1
System isometric
A. 2
Radiant/convector and ice coil tubing . . . . . . . 58
B. 1
Refrigerant, water, and brine flow diagram . . . . 62
B. 2
General arrangement . . . . . . . . . . . 67
B. 3
Elementary wiring diagram . . . . . . . . . 68
B. 4
R-22 piping isometric . . . . . . . . . . . 69
B. 5
Water and brine piping isometric . . . . . . . 70
B. 6
Stee1 framework . . . . . . . . . . . . 71
B. 7
Enclosure panel details . . . . . . . . . . . 72
B. 8
New mechanical package . . . . . . . . . . . 73
B. 9
New mechanical package 
ACES DEMONSTRATION: CONSTRUCTION, STARTUP, AND PERFORMANCE REPORT

A. S. Holman

\begin{abstract}
A $2000-f t^{2}$ single-family residence was constructed during the second quarter of 1976 to demonstrate the energyconserving features of additional insulation, a ventilation cooling cycle, and the Annual Cycle Energy System (ACES). The ACES is an integrated heating and cooling system that supplies space heating, hot water, and space cooling using a heat pump and low-temperature thermal storage. Included in this report are a discussion of the construction techniques employed. and the problems encountered during construction, a description of the ACES concept and the ACES mechanical package, and a discussion of the ACES performance and the experiences obtained during initial operation of the ACES. Continuous operation and data collection were begun in May 1977. Performance data from November 1977 through March 1978 have shown a seasonal heating coefficient of performance of 2.77 for the ACES, giving a $63 \%$ energy reduction compared to electric resistance space and water heating.
\end{abstract}

\title{
1. SUMMARY
}

The Annual Cycle Energy System (ACES) demonstration house is a 2000-ft ${ }^{2}$ single-family residence built to demonstrate the energy-conserving features of added insulation, a ventilation cooling cycle, and the ACES. Its primary feature is the use of the ACES - an integrated heating, cooling, and domestic hot-water system that employs a high-efficiency unidirectional heat pump, low-temperature thermal storage, and solar assistallé.

The ACES house is part of a three-house complex located on the University of Tennessee Agriculture Campus near Knoxville, Tennessee. The ACES and the control houses in the complex have the same floor plan as the solar house and similar thermal envelopes so that the three houses exhibit nearly equal heating and cooling loads. The solar house employs 
a solar heating and hot-water system that supplies some portion of the space and water heating loads. The control house uses either resistance heat or an air-to-air heat pump to supply the heating loads, an air-to-air heat pump to supply the cooling loads, and an electric water heater to supply the domestic hot-water loads. The solar house is not discussed in this report, and the control house is discussed only when comparing the energy consumption of the ACES house to the energy consumption of other heațing and cooling systems.

Because of the experimental nature of the ACES demonstration house, some unexpected problems were encountered during the construction and startup period. This report discusses these problems and the steps taken to correct them. The major difficulties encountered during construction arose from the use of (1) $2 \times 6$ in. studs in the sidewalls, (2) styrofoam forms for the basement and foundation walls, and (3) aluminum for the heat transfer surfaces in the ACES. All of these problems have been solved, and a new mechanical package has been installed. The ACES has been operational since May 1977.

Single-mode performance tests were conducted during the summer of 1977, and the full annual cycle was begun on October 31, 1977. Based on the experimental data and computer predictions of building loads, it is possible to estimate the energy saving obtained by the ACES. During the heating season that began on October 31, 197\%, and ended on March 26, 1978, the ACES consumed $4960 \mathrm{kWhr}$ as opposed to $13,200 \mathrm{kWhr}$ consumed by the control house to deliver nearly identical loads, or a $62 \%$ reduction in electrical consumption. For the entire annual cycle the ACES will consume an estimated $70 \%$ less energy than will the control house.

The following are previously published reports relating to the ACES :

H. C. Fischer, Summary of Annual Cycle Energy System Workshop I held October 29-30, 1975, at Oak Ridge, Tennessee, ORNL/TM-5243 (July 1976).

E. C. Hise, J. C. Moyers, and H. C. Fischer, Design Report for the ACES Demonstration House, ORNL/CON-1 (October 1976). 
H. C. Fischer et al., The Annual Cycle Energy System Initial Investigations, ORNL/TM-5525 (October 1976).

E. C. Hise, Performance Report for the ACES Demonstration House August 1976 through August 1977, ORNL/CON-19 (March 1978). 
THIS PAGE

\section{WAS INTENTIONALLY LEFT BLANK}




\section{PROJECT DESCRIPTION}

\subsection{The House}

\subsubsection{Architectura1}

The ACES house construction is similar to that of the solar house, which was designed by students and faculty of the University of Tennessee Department of Architecture. Figures 2.1, 2.2, and 2.3 show the basement floor plan, the first floor plan, and the second floor plan respectively. Figure 2.4 is an artist's conception of the exterior appearance of the house. The house has three bedrooms, two baths, a kitchen, living room, mechanical equipment room, entrance vestibule, and partial basement. A portion of the basement is used to house the ice-and-water thermal ștorage bin. ${ }^{1,2}$

\subsubsection{Thermal envelope}

The thermal envelope specifications for the ACES demonstration house exceed those specified by HUD Minimum Property Standards 3 for a residence located in the Knoxville area. Table 2.1 lists the "U" values specified by HUD Minimum Property Standards and those for the house as built. To obtain the lower $U$ values, the house was built using $2 \times 6$ in. studs in the sidewalls and $2 \times 12 \mathrm{in}$. floor and ceiling joists. Six inches of fiberglass insulation were placed in the sidewalls, over the basement ceiling, and over the cathedral ceiling, giving an overall "R" value for these surfaces of 22 ( $R$ values are measured in $\mathrm{hr} \cdot \mathrm{ft}^{2} \cdot{ }^{\circ} \mathrm{F} / \mathrm{Btu}$ ). Twelve inches of fiberglass insulation were placed over the flat ceiling, crawl space, and thermal storage bin, giving an overall $\mathrm{R}$ value for these surfaces of 42 . The basement and crawl space walls were constructed using reinforced concrete pourcd in styrofoam molds. This composite wall construction has a claimed overall $R$ value of 16 .

Attention was also given to the doors and windows to minimize heat loss or gain and infiltration to the house. The one exterior door and two interior doors leading from the vestibule are metal foam-core doors with an $R$ value of 8 and were installed with magnetic weather stripping 


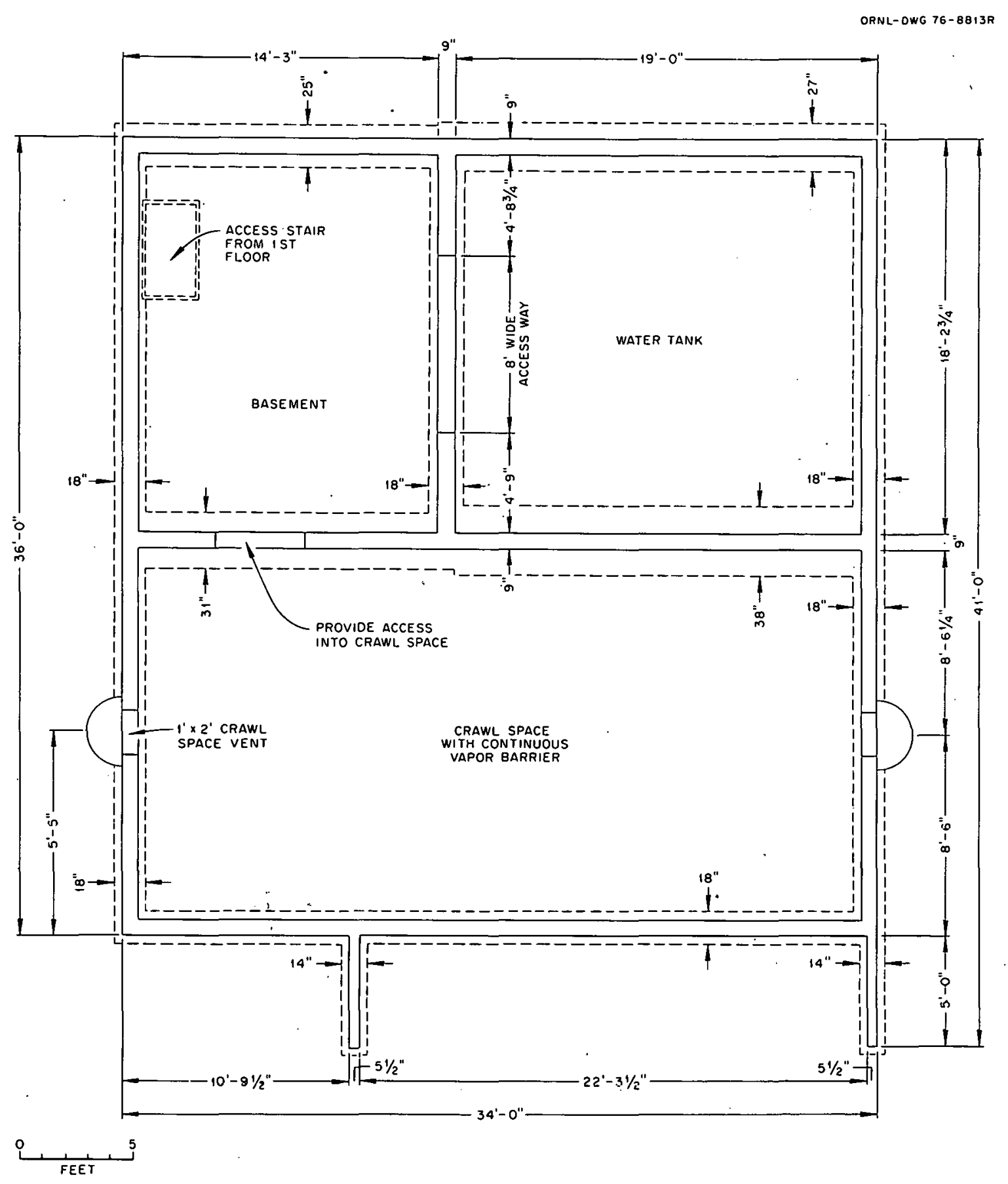

Fig. 2.1. Basement plan. 


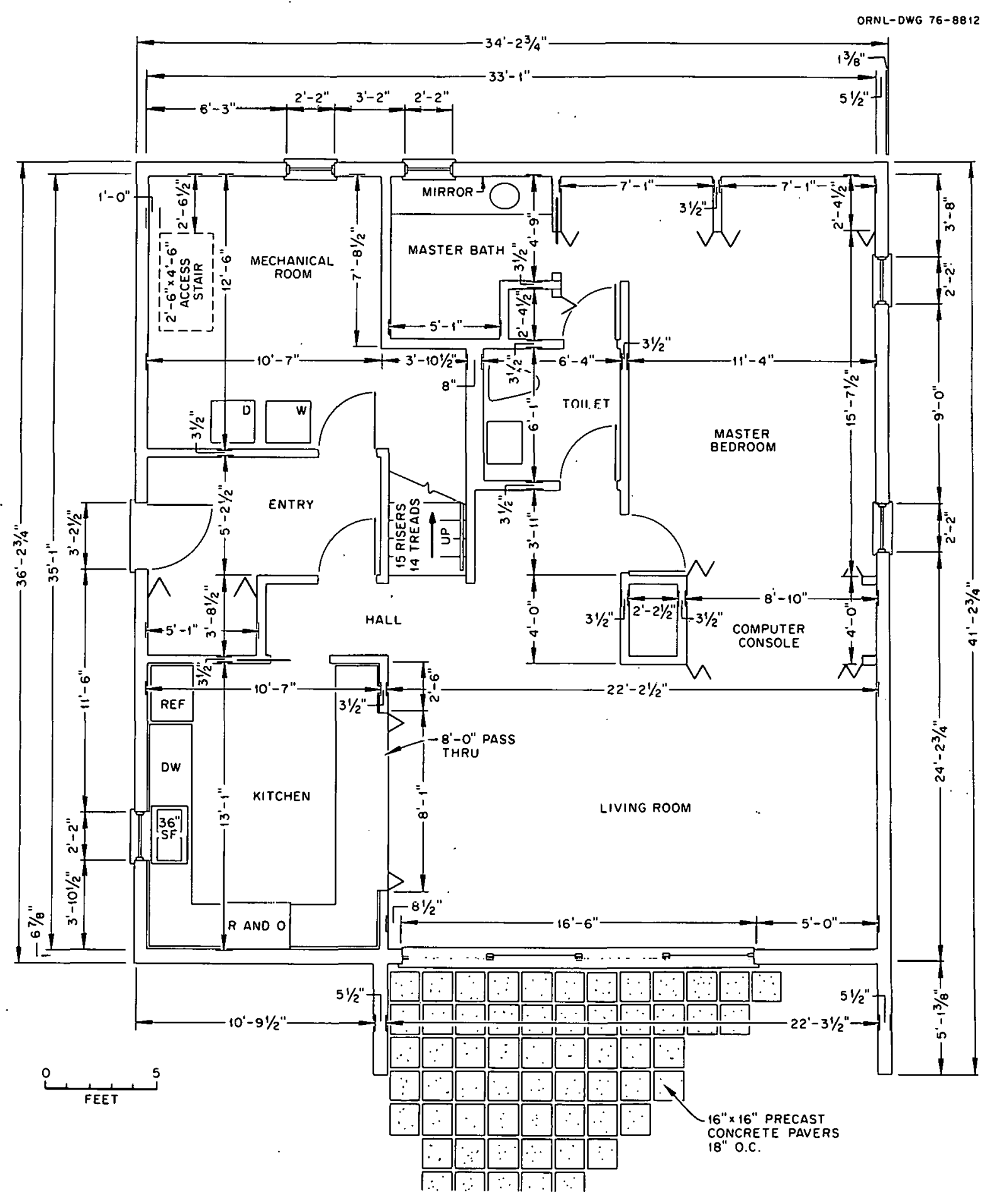

Fig. 2.2. First floor plan.' 
ORNL-DWG 76-8811

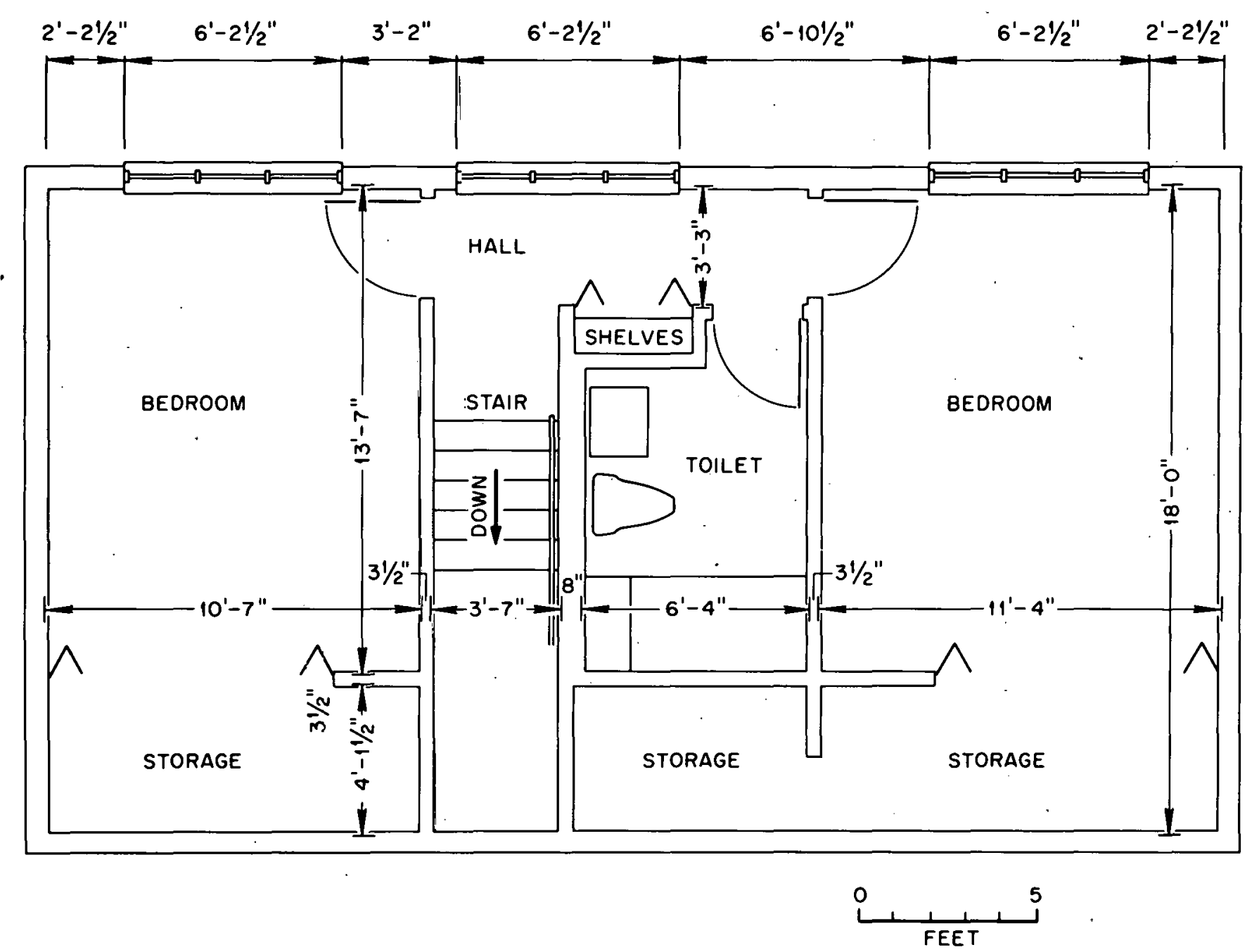

Fig. 2.3. Second floor plan. 


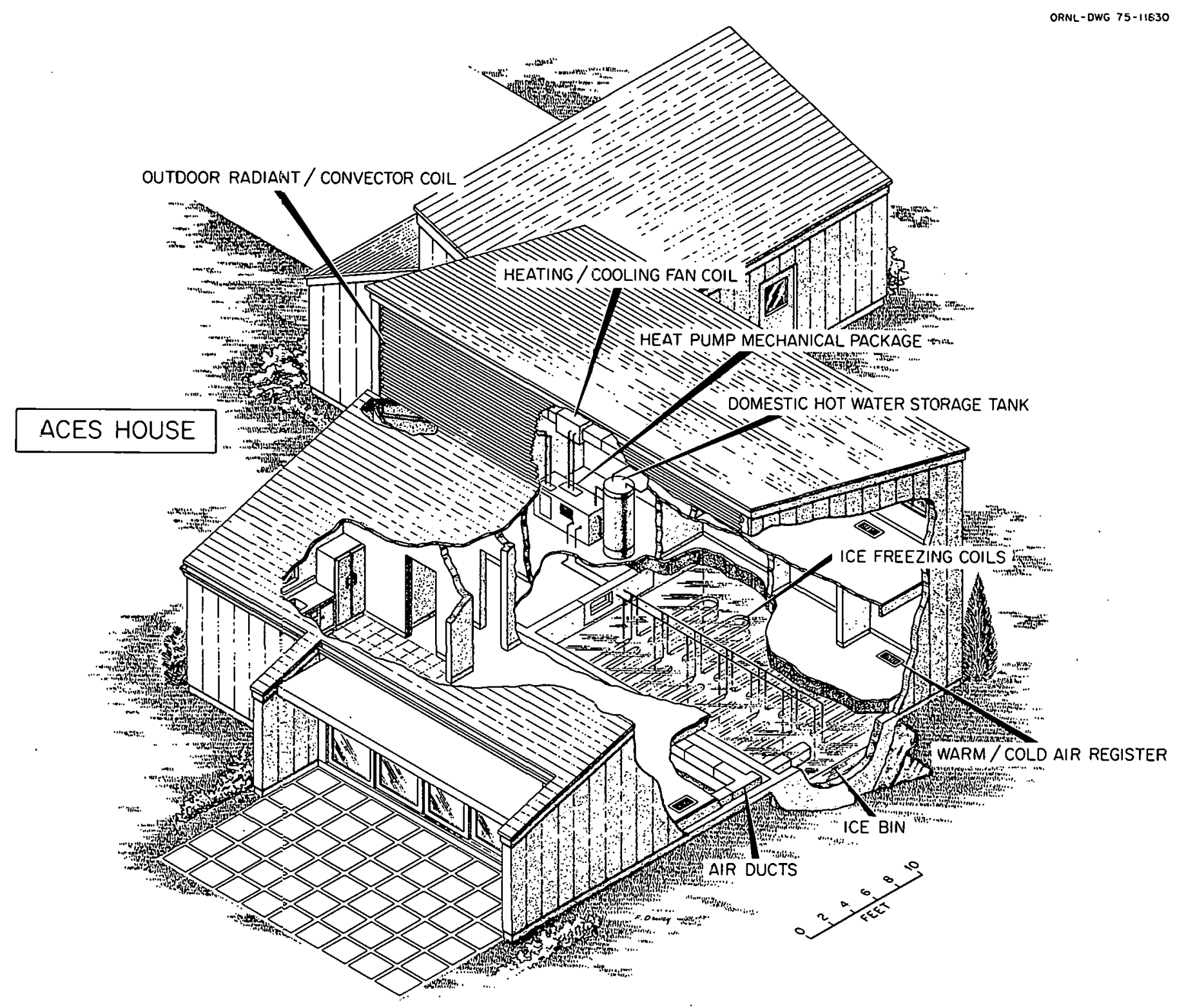

Fig. 2.4. Artist's conception of ACES house. 
Table 2.1. Insulation details

\begin{tabular}{|c|c|c|c|c|}
\hline & \multicolumn{2}{|c|}{ Demonstration house } & \multicolumn{2}{|c|}{$\begin{array}{l}\text { HUD minimum property } \\
\text { standards }\end{array}$} \\
\hline & Insulation & $u$-value ${ }^{a}$ & Insulation & U-value ${ }^{a}$ \\
\hline Sidewalls & $51 / 2 \mathrm{in.}$ & 0.045 & Not specified & 0.08 \\
\hline Ceiling, flat & 12 in. & 0.024 & & 0.05 \\
\hline Ceiling, cathedral & 6 in. & 0.040 & & \\
\hline $\begin{array}{l}\text { Floor (over crawl } \\
\text { space) }\end{array}$ & 6 in. & 0.040 & & 0.10 \\
\hline $\begin{array}{l}\text { Floor (over ice } \\
\text { bin) }\end{array}$ & 12 in. & 0.024 & & \\
\hline Windows & Double glazed & 0.58 & Single glazed & 1.12 \\
\hline $\begin{array}{l}\text { Basement and crawl } \\
\text { space }\end{array}$ & & 0.062 & & \\
\hline
\end{tabular}

$a_{\mathrm{U}-\mathrm{value}}$ in $\mathrm{Btu} / \mathrm{hr} \cdot \mathrm{ft} \mathrm{t}^{2} \cdot{ }^{\circ} \mathrm{F}$.

to reduce air infiltration. The windows and sliding glass doors are double-glazed thermopane glass having an $\mathrm{R}$ value of $1.7 .1,2$

\section{1 .3 Building loads}

Specification of certain components of the ACES mechanical package required an estimate of the design day heating and cooling loads. These loads are independent of the type of heating and cooling system employed, depending only on the thermal envelope of the house and the indoor and outdoor design conditions. The thermal envelope is described fully in Table 2.1, which gives the various U values; Table 2.2, which gives the areas and exposures; and Table 2.3, which gives the various types of construction. The inside and outside design conditions are listed in Table 2.4.

The design day heating and cooling loads represent the rate at which energy must be added to or removed from the house to maintain the desired indoor conditions when the outdoor conditions are those specified in 
Table 2:2. Areas and exposures

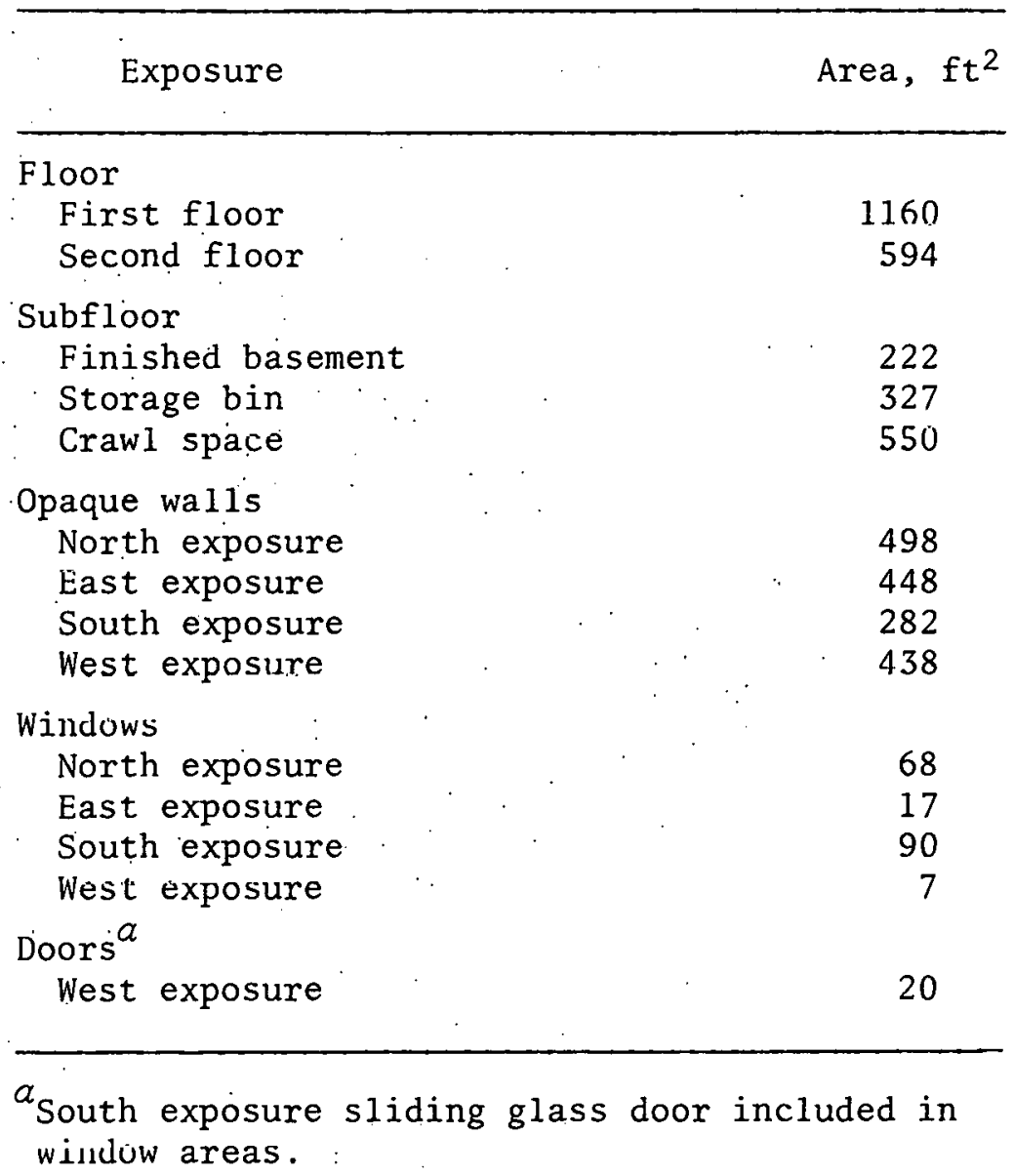


Table 2.3. Construction details

Exterior walls

Ceiling

Roof

Floor

Windows

Door 1/2-in. gypsum board, $2 \times 6$ studs 16 in. O.C. with $51 / 2$-in. glass fiber batt insulation, 25/32-in. fiber board sheathing, 5/8-in. exterior plywood

(760 $\mathrm{ft}^{2} \mathrm{flat}$ ) 1/2-in. gypsum board, $2 \times 4$ trussed joists with 12-in. glass fiber batt insulation

(367 $\mathrm{ft}^{2}$, horizontal projection, cathedral) 1/2-in. gypsum board, $2 \times 12$ rafters with 6 -in. glass fiber batt insulation, 5 1/2-in. vented air space, 5/8-in. plywood sheathing, building paper, asphalt shingles

(over flat ceiling, $760 \mathrm{ft}^{2}$ ) $2 \times 4$ trussed rafters, $5 / 8$-in. plywood sheathing, building paper, asphalt shingles

Carpet or sheet vinyl, 5/8-in. particle board underlayment, building paper, 5/8-in. plywood subfloor, $2 \times 12$ joists with $51 / 2-i n$. air gap and 6-in. glass fiber insulation

Double-glazed, wood frame

Metal cased, $13 / 4$-in. urethane foam core, with magnetic weather seal

Table 2.4. Inside and outside design conditions ${ }^{a}$

Summer

Winter

Inside dry bulb, ${ }^{\circ} \mathrm{F}$

78

Inside relative humidity, $\%$

60

Internal load, electrical, $\mathrm{kW}$

1

1

Internal load, people

$2-4$

$2-4$

Ventilation, air changes/hr

0.5

0.5

Outside dry bulb, ${ }^{\circ} \mathrm{F}$

95

17

Outside wet bulb; ${ }^{\circ} \mathrm{F}$

77

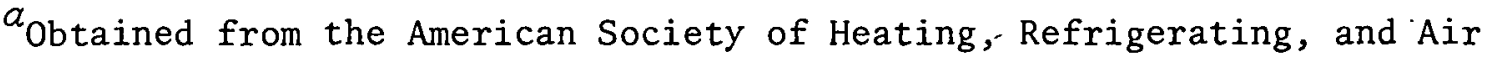
Conditioning Engineers. 
Table 2.4. Table 2.5 contains the design day and seasonal loads for the house as built, or as insulated to HUD Minimum Property Standards, 3 and employing a ventilation cooling cycle. It is useful to calculate each of these loads so that the effects of the added insulation and the ventilation cycle can be seen separately.

Table 2.5. Design heating and cooling loads and seasonal requirements ${ }^{a}$

\begin{tabular}{lccc}
\hline & $\begin{array}{c}\text { Insulated to HUD } \\
\text { minimum property } \\
\text { standards }\end{array}$ & $\begin{array}{c}\text { Demonstration } \\
\text { house }\end{array}$ & $\begin{array}{c}\text { Demonstration } \\
\text { house with } \\
\text { economy cycle }\end{array}$ \\
\hline Design heating load, Btu & 29,790 & 18,230 & 18,230 \\
$\begin{array}{l}\text { Design cooling load, Btu } \\
\begin{array}{l}\text { Seasonal heating } \\
\text { requirement, MBtu }\end{array}\end{array}$ & 23,760 & 19,000 & 19,000 \\
$\begin{array}{l}\text { Seasonal cooling } \\
\text { requirement, MBtu }\end{array}$ & 43.8 & 20.3 & 20.3 \\
\hline
\end{tabular}

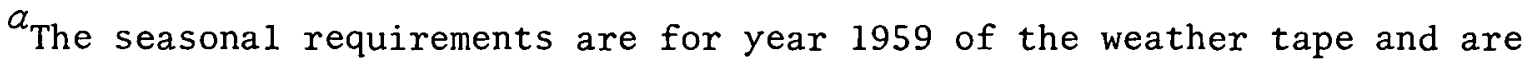
representative, although not necessarily average.

Table 2.5 shows that the house as built has a design day heating load equal to $61 \%$ of that for a conventionally insulated home and a cooling load equal to $80 \%$ of the conventional home. The lower heating-to-cooling ratio reflects the fact that the internal loads dccrcasc the heating reyuirements and increase the cooling requirements by amounts that vary with the extent of insulation.

Although representing the loads to be met by the heating and cooling system for design day conditions, these design day loads do not indicate the total amount of heating or cooling required by the house during the year. An estimate of these yearly requirements was necessary to approximate the energy consumption of the heating and cooling system and to size the ACES thermal storage bin. Several computational methods for calculating these requirements are available. The computer method chosen for this project used hourly weather data recorded for the Knoxville area during the years 1955-1962. 
The estimated annual heating requirements for the house as built are only $46 \%$ of those for a conventionally insulated home, but the cooling requirements are $106 \%$ (Table 2.5 ). These figures again reflect. the effect of the internal loads on a well-insulated home. The cooling requirements for the house can be reduced $29 \%$ by employing a ventilation cooling cycle. The demonstration house employs this cycle, and column 3 of Table 2.5 represents the estimated heating and cooling loads for the as-built house. 1,2

\subsection{The ACES}

\subsubsection{The ACES concept}

The ACES is an energy-conserving, load-leveling; integrated heating and cooling system that provides space heating, space cooling, and domestic hot water. The ACES concept relies on the fact that a heat pump must extract heat from some external source to provide heating. In a conventional heat pump system, this external source is the outside air accessed by an outdoor air unit. In the ACES, the outside air unit is replaced with ice-freezing coils located in an ice-and-water thermal storage bin, and the external source is the heat of fusion of water as it is converted to ise.

During the heating season, as the compressor operates to supply the heating demands, water is gradually converted to ice in the thermal storage bin. When space cooling must finally be supplied, operating the compressor as in a conventional air conditioning system is unnecessary; rather, the ACES need only melt stored ice to meet the cooling demands. Because the compressor does not operate to meet the cooling loads, energy savings are obtained over a conventional heat pump system. Additional energy savings are obtained by producing the domestic hot water with the compressor at a coefficient of performance (COP) of approximately 3 as opposed to using electric resistance water heating at a COP of 1 . Being a fixed-capacity system, the ACES further reduces energy consumption by not requiring the use of supplemental resistance heaters. Consequently, the ACES can deliver all of the space heating at a nearly constant COP 
of 2.7, even during the coldest parts of the winter, whereas a conventional heat pump would drop to a COP of approximately 1.3 under those conditions.

Because the ACES employs a finite heat source as opposed to the nearly infinite heat source used by a conventional heat pump system, some mechanism for balancing the ACES must be provided. This balancing is provided by a single outdoor radiant/convector panel used either to accept or to reject heat. If, during the heating season, too much of the water in the thermal storage bin is being converted into ice, the solar panel can be used to accept heat from the sun (and/or the ambient air if the temperature is in excess of $32^{\circ} \mathrm{F}$ ) to melt some of the ice. If, on the other hand, the ice supply in the thermal storage bin has been exhausted before the end of the cooling season, the panel can be used at night to reject heat from the compressor. This nighttime operation of the compressor, which produces ice in the thermal storage bin for later use in space cooling, provides off-peak load leveling even when the winter ice supply has been exhausted.

\subsubsection{ACES modes of operation}

The ACES, shown in the schematic flowsheet of Fig. 2.5, is composed of a compressor, four refrigerant-to-brine heat exchangers, a fan coil, an outdoor panel, a domestic hot-water storage tank, a thermal storage bin, and the appropriate piping and valving to interconnect the various components. The brine in the ACES is a solution of $25 \%$ methanol by volume in water. By employing various valving arrangements, the ACES has nine distinct modes of operation. Three of these modes perform the primary functions of space heating, space cooling, and domestic hot-water production; two of the modes perform the balancing functions of ice melting and night heat rejection; and the remaining four modes result from combinations of the previously mentioned modes occurring simultaneously.

The schematic diagram for space heating is shown in Fig. 2.5. When space heating is called for, all pumps, the compressor, and the fan are in operation, with the only idle component being the domestic hot-water 


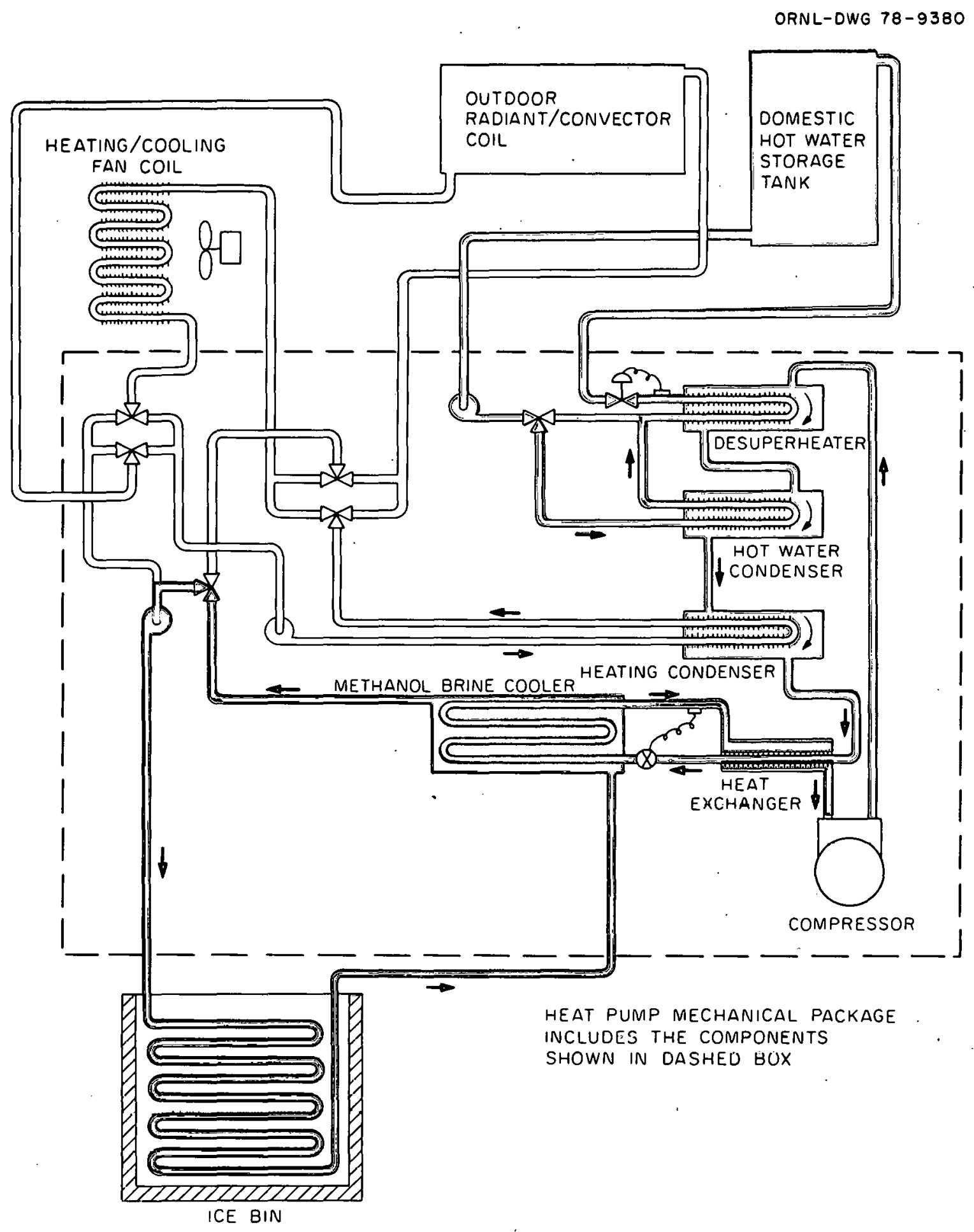

Fig. 2.5. Space heating schematic. 
condenser. Space heating is delivered to the fan coil from the space heating condenser, and domestic hot water is produced using the superheat obtained from the domestic hot-water desuperheater. Heat is extracted from the thermal storage bin by the evaporator, causing some of the water to be converted into ice to be used to meet future space cooling demands.

The second major function of the ACES, providing domestic hot water, is automatically performed whenever space heating is called for, but quite often this amount of hot water is not sufficient. For those occasions, the ACES is capable of providing domestic hot water only. In this mode of operation, shown in the schematic diagram in Fig. 2.6, the compressor and the hot water and cooling pumps are in opcration. Heat, which is extracted from the thermal storage bin by the evaporator to form ice in the bin, is delivered to the hot water through the domestic hot-water condenser and desuperheater acting in series. The ice produced in this mode is also saved to meet later space cooling loads.

The simplest of the primary modes of operation is that of space cooling, which is shown schematically in Fig. 2.7. The fan and the cooling pump are the only electrical components in operation during this mode. Space cooling is delivered by circulating chilled brine from the thermal storage bin to the fan coil, which causes some of the ice in the thermal storage bin to melt, thereby delivering space cooling to the home.

If a climate were so balanced that the ice produced while delivering space heating and domestic hot water were exactly equal to that needed to provide space cooling, no addilivilal mules of opcration would be needed. However, because this is not the case, some method of balancing the ACES must be included. Northern climates necessitate melting some of the ice produced while still being able to supply the summer cooling requirement. Southern climates necessitate making extra ice when the supply has been exhausted. These two external balancing modes are provided by ice melting and night heat rejection, which arc shown schematically in Figs. 2.8 and 2.9 respectively. Ice melting is accomplished by circulating chilled brine from the thermal storage bin to the outdoor panel where heat from the sun, and/or the ambient air if the temperature exceeds $32^{\circ} \mathrm{F}$, raises the brine temperature and causes 
ORNL-DWG 78-9377

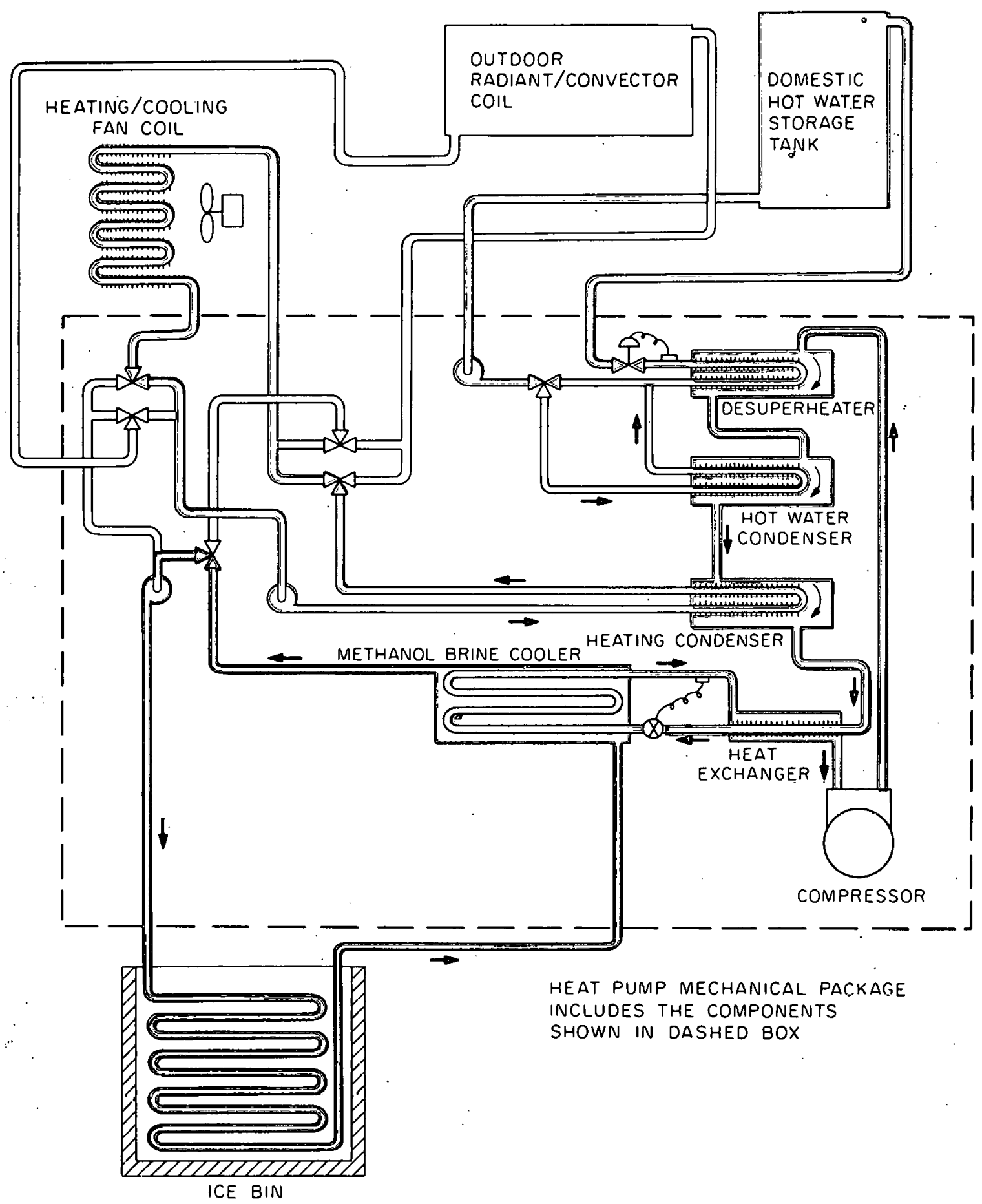

Fig. 2.6. Hot water schematic. 


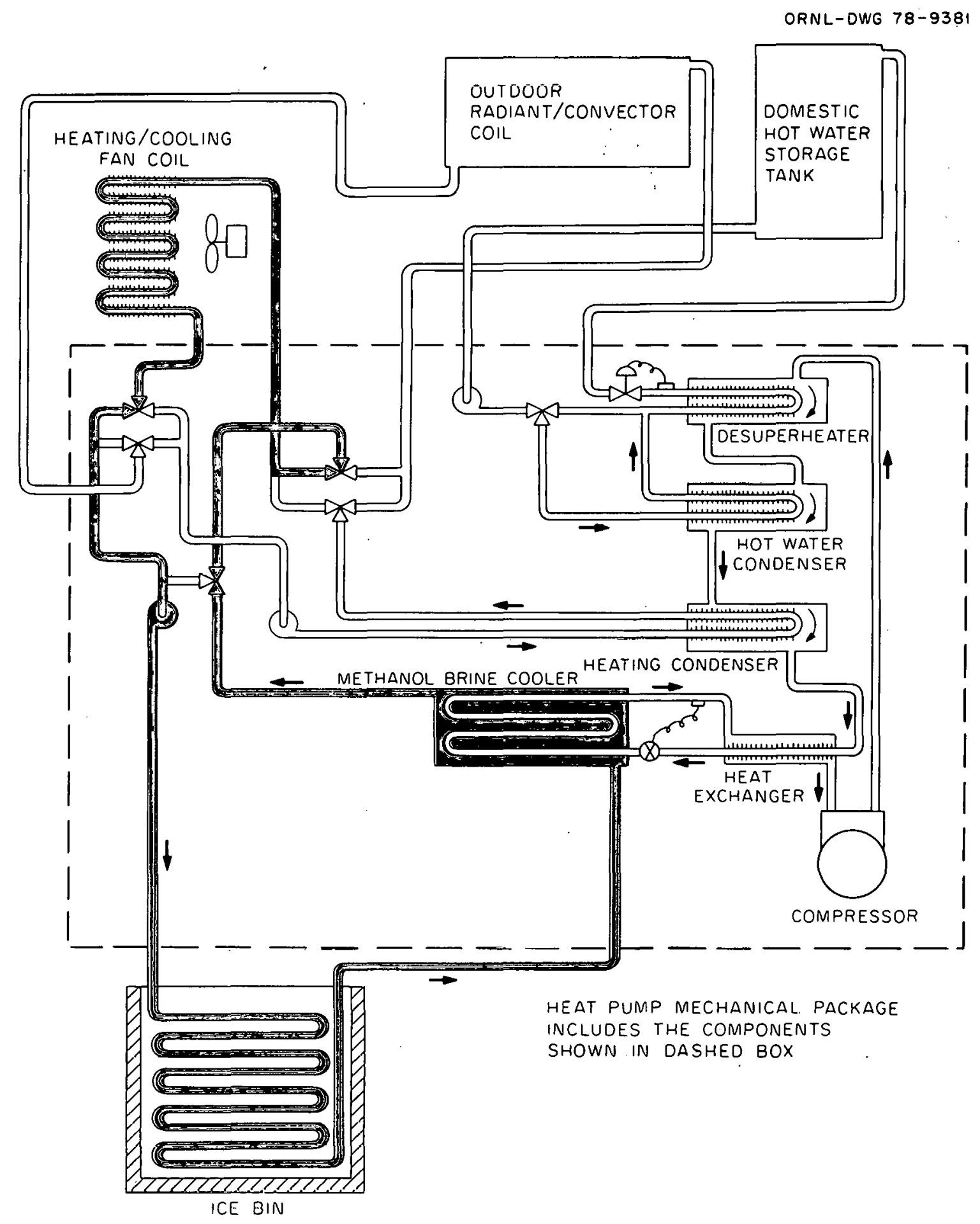

Fig. 2.7. Space cooling schematic. 


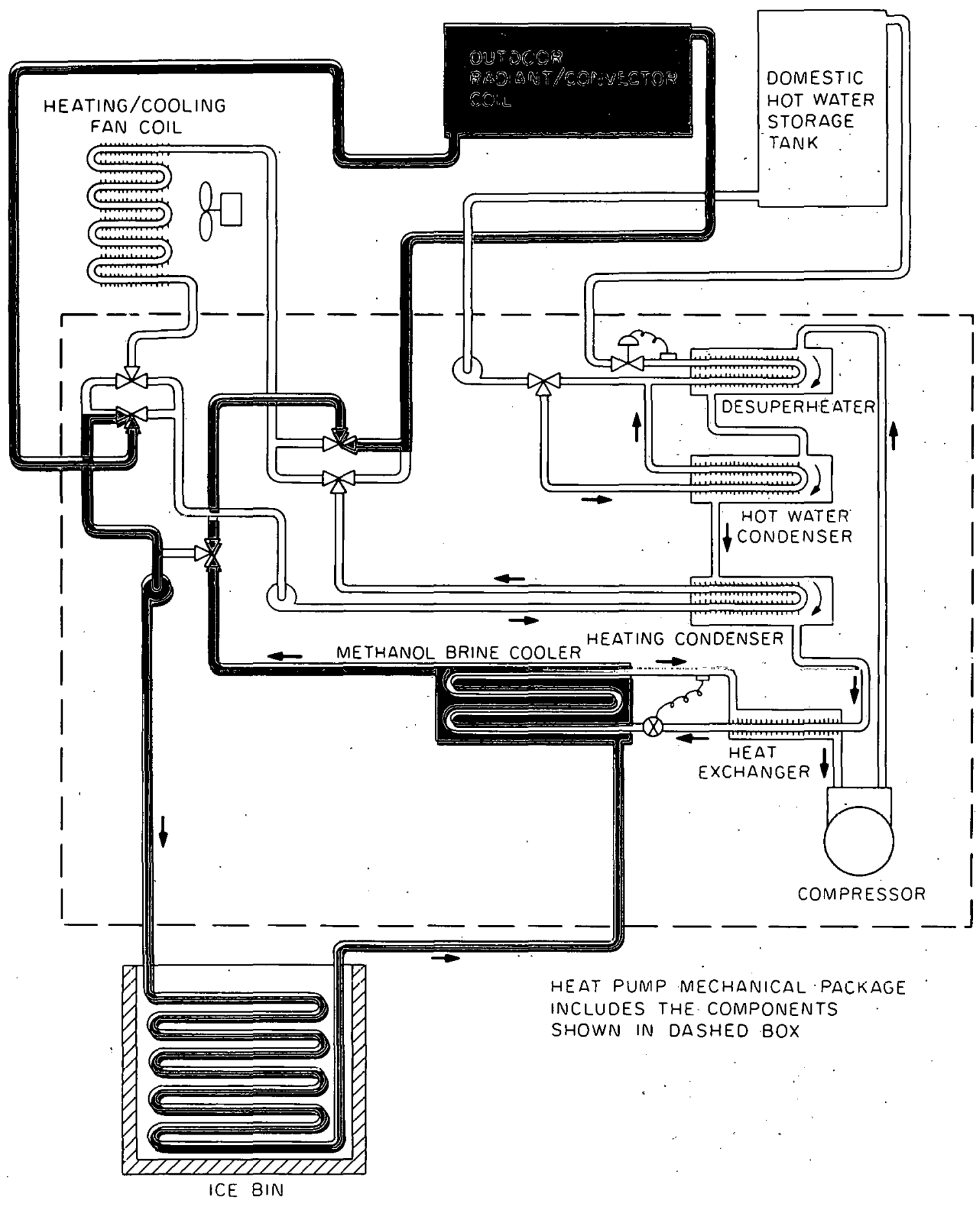

Fig. 2.8. Ice melt schematic. 


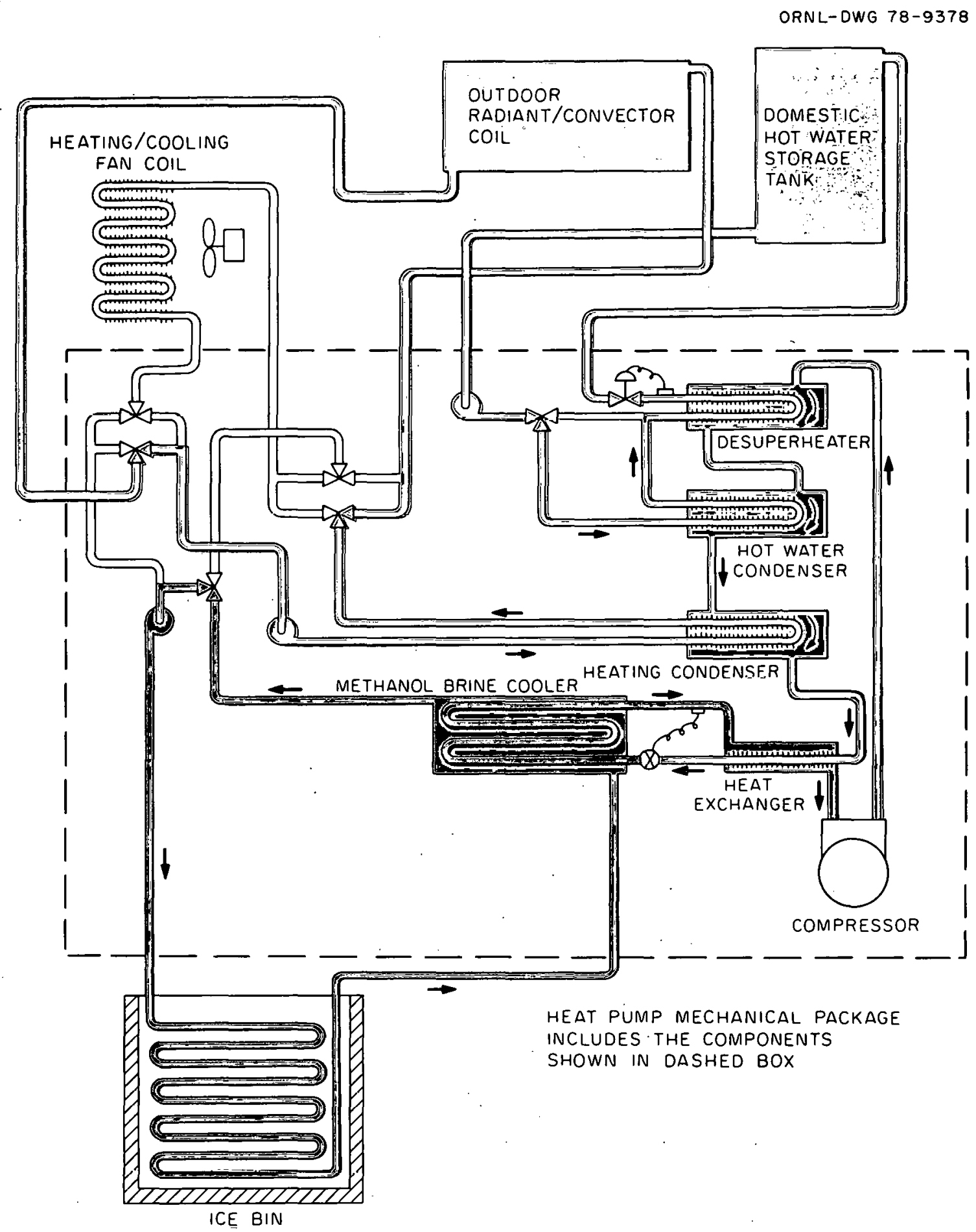

Fig. 2.9. Night heat rejection schematic. 
some of the ice to be melted. The only electrical device operating during this mode is the cooling pump. Night heat rejection is accomplished by extracting heat from the thermal storage bin, thereby producing ice and placing some of this heat into the domestic hot water, with the excess heat being rejected through the outdoor panel. This mode requires that the compressor and all pumps be in operation.

In addition to the five modes previously mentioned, four additional modes are obtained by various combinations of those five modes operating simultaneously. These additional modes are space heating with ice melting, domestic hot-water production with ice melting, space cooling with domestic hot-water production, and space cooling with night heat rejection. In these modes, each of the functions are performed as if they were being executed independently.

\section{2 .3 ACES features}

The ACES offers two major features that make it very attractive when compared with conventional heating and cooling systems. For the consumer, the ACES offers a reduction in the amount of electricity consumed in providing space heating, space cooling, and domestic hot water. For the utility, the ACES provides load-leveling and peak demand reduction capabilities automatically without the utility having to control the heating and cooling systems remotely or having to rely on the consumer to pcrform voluntary load leveling. With the introduction of time-of-day metering and lower off-peak rates, these load-leveling capabilities will becone economically attractive to the consumer as well.

The ACES reduces electrical consumption in a number of ways, one of which is a deferred saving resulting from the use of stored ice to provide nearly free space cooling. During the period before the ice supply has been exhausted, which varies from climate to climate, ACES supplies space cooling at a COP of approximately 13 as compared to a COP of approximately 2 to 3 for conventional cooling systems. The result is an electrical saving of 77 to $85 \%$ over conventional systems. When the stored ice has been exhausted and night heat rejection is required, the ACES COP for cooling is nearly the same as that for a 
conventional system. However, the ACES produces domestic hot water under these conditions as a by-product of compressor operation.

Electrical consumption is also reduced during the heating season. This saving results because the ACES is a fixed-capacity system and uses the heat pump to heat the hot water. Being a fixed-capacity system, the ACES has no need for supplemental electric resistance heating to meet the heating loads on extremely cold days and can maintain a high average COP during the heating season.

Preliminary estimates indicate that in the Knoxville area the ACES consumes approximately $51 \%$ less energy annually than a conventional heat pump system with a seasonal COP of 2 and an electric resistance hot-water heater, and 63\% less energy than an electric furnace, a central air conditioning system with a cooling COP of 2 , and an electric resistance hot-water heater. Section 5 contains a complete discussion of the performance of the ACES using actual performance data gathered from the demonstration liouse.

The load-leveling capabilities of the ACES are threefold and should be particularly attractive to the electric utilities. First, during the heating season a significant reduction in peak demand is obtained because of the uniformly high COP that is maintained by the ACES independent of outside temperatures. Second, during the cooling season when stored ice is still available, cooling is provided with very small electrical usage. Third, during the cooling season when the ice supply has been exhausted, cooling is provided by operating the compressor during the off-peak night hours to provide for future cooling requirements.

By using stored ice to provide space cooling, the peak demand for space cooling is 77 to $85 \%$ less than that required by conventional cooling systems. When the ice supply has been exhausted, the load imposed by the ACES during the utility's peak load period in the afternoon is the salle 77 to $85^{\circ}$ less than conventional air conditioners because the compressor is not operating during the high-peak afternoon hours. 
THIS PAGE

\section{WAS INTENTIONALLY LEFT BLANK}


3. CONSTRUCTION, INSTALLATION, AND OPERATIONAL EXPERIENCE

\subsection{House Construction}

The ACES demonstration house was designed to be energy conserving not only with respect to its heating and cooling system but also with respect to the building structure. Thus, several energy-conserving construction techniques were employed: (1) the use of $2 \times 6$ in. studs in the sidewalls and R-19 insulation; (2) the use of styrofoam forms ("Foam Form") to build the basement, crawl space, and thermal storage bin walls; (3) metal foam-core doors with magnetic weather stripping; (4) thermopane glass; (5) the use of a vestibule to reduce air infiltration from door openings. Because of these techniques, some unexpected problems were encountered during construction that are discussed in the following sections.

\subsubsection{Thermal storage bin walls}

The thermal storage bin walls were built using the Foam Form block technique mentioned previously and described in Fig. 3.1. Foam Form was selected because it provides a claimed installed insulating $\mathrm{R}$ value of approximately 16 without adding any additional insulation. Foam Form is laid in courses, very similar to brick, over the footing. To strengthen the walls, horizontal and vertical reinforcing bars were added. Foam Forms are laid two courses at a time, and then filled with concrete, after which annther two courses are laid and the process continues until the wall is finished. Figures $3.2,3.3$, and 3.4 show the construction of the storage bin walls at various stages of completion using Foam Form blocks. The interior surfaces of these walls were later coated with a petroleum-base product called Nokorode to ensure further that the thermal storage bin would be watertight and to prevent possible corrosion of the aluminum heat exchanger coils from the alkalinity of the concrete.

The manufacturer of Foam Form supplies a construction procedure that has been found to yield an excellent wall construction. According to the manufacturer, Foam Form walls should be constructed using a 


\section{FOAM FORM BLOCK For On The Site Construction of INSULATED STORAGE TANKS For Hot Water or lce}

FOAM FORM blocks are in stock in the 6" core size $19^{\prime \prime}$ outside) and each block has a face area of 5.33 sq. ft. Block dimensions are $48^{\prime \prime}$ long by $16^{\prime \prime}$ high and thickness (over insulation) is $9^{\prime \prime}$. Weight per block is approximately 4 pounds. These blocks consist of two parallel molded sections of expanded polystyrene insulation held together by expanded metal ties. Our Part No. 5878.

To construct a tank of any size required, soil is excavated and a reinforced concrete slab poured. In pouring the slab, vertical steel rods are positioned to pass through the center of the Foam Form blocks. Foam Form blocks are then assembled (tongue and groove) by dropping over the verticle rods. Horizontal steel reinforcing rods are laid inside each tier of Foam Form blocks. Corners are easily formed by mitring at $45^{\circ}$. Temporary bracing is used to keep corners and walls true while pouring.

The surface may then be covered inside and out with "Block Bond" or equivalent to watèr pruol lle fudıI insulatlon. Or a vinyl liner may be used.

By use of Foam Form, a poured concrete tank may be constructed on the job to exactly fit the application and with a minimum of expense for forms.

The form becomes the permanent insulation and the insulating value is approximately $\mathrm{R} 16$.

It is useful for most water or ice storage requirements, including the ACES (Annual Cycle Energy System) since it provides great flexibility and excellent insulation and relatively low cost.
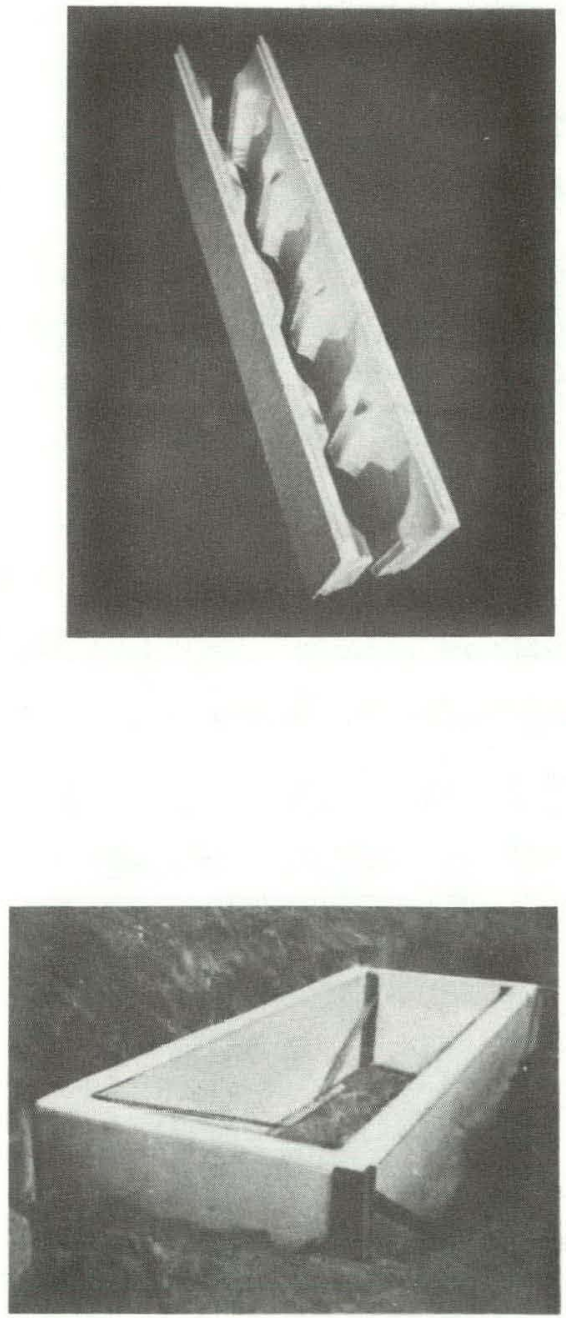

$(\leftrightarrow)$ FOAM FORM is a registered trade mark of FOAM FORM Canada, Ltd., Scarborough, Ontario.

Fig. 3.1. Foam Form. 


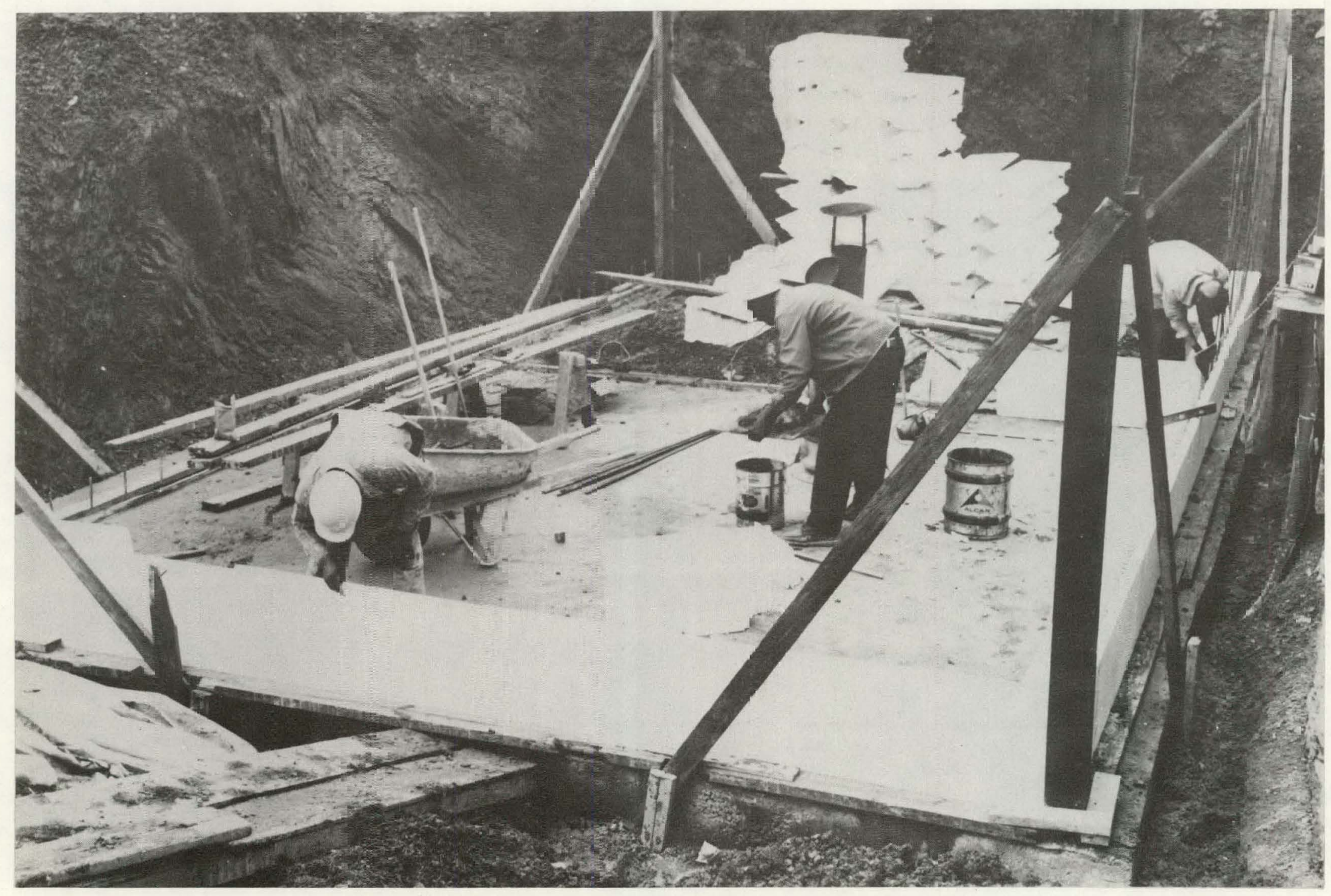

Fig. 3.2. Styrofoam forms at ACES house. (Photograph courtesy of Fennessee Valley Authority.) 


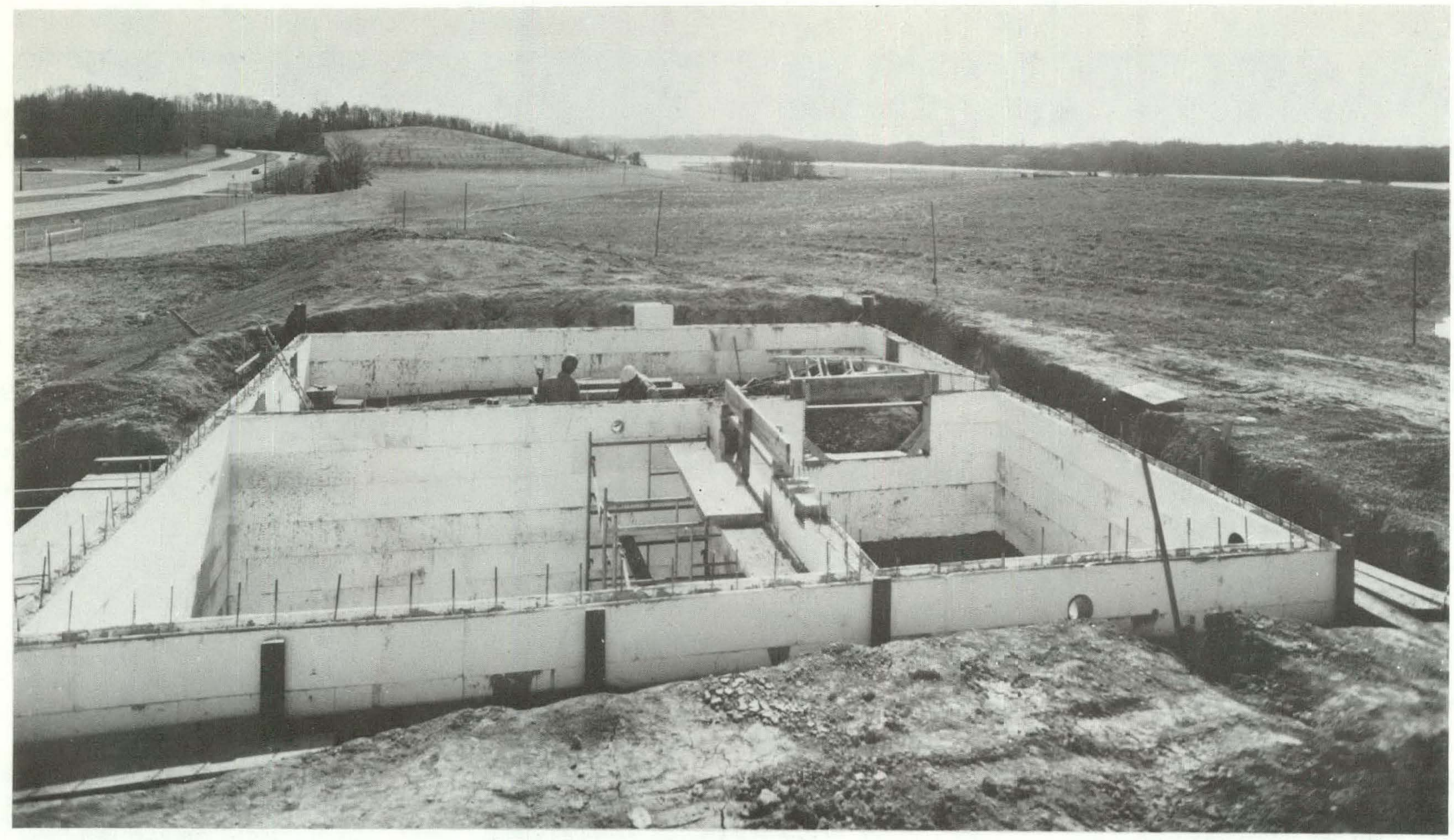

Fig. 3.3. Looking south at A.CES house. (Photograph courtesy of Tennessee Valley futhor_ty.) 


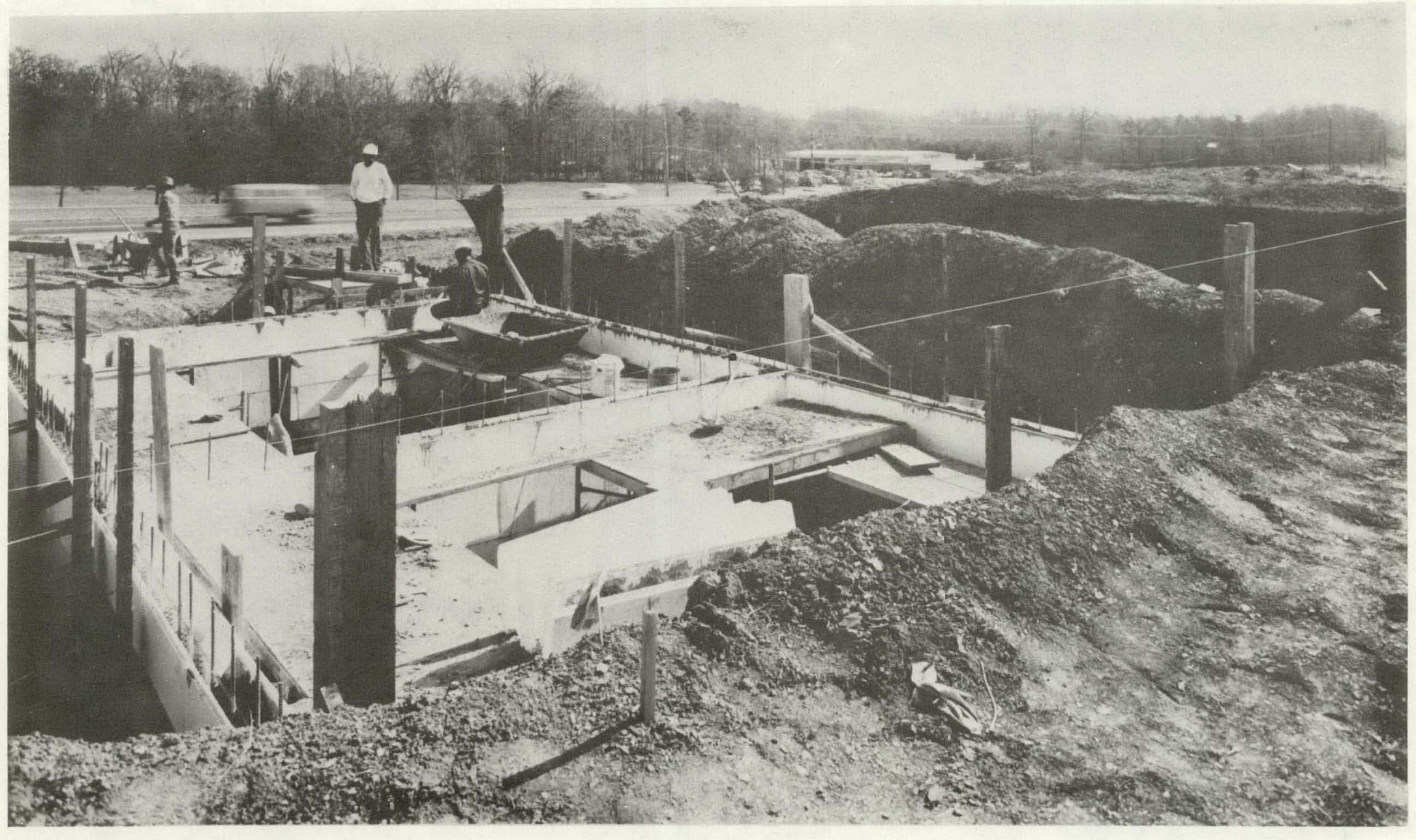

Fig. 3.4. Four courses of styrofoam forms in place at ACES house. (Photograph courtesy of Tennessee Valley Authority.) 
continuous pour technique. The contractor should lay two courses of Foam Form and then begin to pump No. 4 slump concrete into these forms. While the pumping is in progress, the next two courses of Foam Form should be laid and the reinforcing bars tied so that pumping between courses is not discontinued. This technique creates no "cold" joints between courses of concrete, thereby producing a wall that is watertight. However, the construction contractor for the ACES demonstration house was unable to pump the concrete in the required continuous manner because he lacked the necessary equipment, which resulted in a wall with numerous cold joints that was not watertight. Corrective steps had to be taken later to make the storage tank watertight.

Another problem occurred during construction of the thermal storage bin walls after the first two courses had been laid. It became necessary to brace the walls with $2 \times 12$ in. studs to keep the blocks from separating at the seams and allowing the concrete to seep out because the concrete used was not No. 4 slump concrete as specified by the manufacturer.

\subsubsection{Exterior wall framing}

To allow for the $51 / 2$ in. of insulation, the exterior walls were constructed using $2 \times 6$ in. studs on 16-in. centers. The interior partitions were constructed using typical $2 \times 4$ in. studs on 16-in. centers. The use of $2 \times 6$ in. studs created some minor problems during construcliun, the most noticeable of which was simply weight. The larger studs increased the weight of the exterior walls and therefore required more manpower to position them, which of course increased the cost of construction.

Because of the extra thickness of the exterior walls, the standard window and door jambs were not wide enough to trim properly. The window jambs were modified by adding a small strip of gypsum board on the inside, but because there appeared to be no easy way of modifying the door jambs, they were custom made. These problems also increased the cost of construction.

The report entitled Energy Saving Homes - The Arkansas Story ${ }^{4}$ indicates that the increased cost of construction suffered by this project need not occur. This report gives detailed specifications on how to build 
an energy-conserving home using $2 \times 6$ in. studs in the sidewalls and other energy-saving features without increasing the cost of construction. It indicates that in many circumstances the cost of construction may well decrease if the home is constructed using the techniques presented.

\section{1 .3 Ceiling}

The only problem encountered during construction of the ceilings involved insulating the cathedral ceiling. Because of the construction technique employed, only 9 in. of insulation could have been installed instead of the $12 \mathrm{in.}$ in the other portions of the ceiling. Instead of installing 9 in., which would have required installing both a 6 - and a 3 -in. batt, the cathedral ceiling was insulated with only 6 in. of insulation.

\subsection{ACES Installation}

Because of the experimental nature of the ACES, some difficulties were encountered during the installation process. The following sections discuss the installation procedures, the difficulties encountered, and the steps taken to remedy these difficulties.

\subsubsection{Ice-and-water storage bin}

Figures 3.5 and 3.6 show the installation of the ice-freezing coils at various stages of completion. After being installed in the storage bin, the coils had to be connected to the headers already installed over the bin, which was accomplished using short pieces of flexible hose and ordinary hose clamps. Although this type of connection is quite satisfactory in most applications, the fact that the aluminum tubing used to make the coils was thin-wall (0.030-in.) made it impossible to apply much pressure to the hose clamps without collapsing the tubing. When this configuration was pressure tested, it was discovered that many of the connections leaked. To correct this problem, the connections were remade using RTV silicone rubber as a seal and adhesive. Retesting showed no leakage, and this technique has now been used for all connections wilh excellent results. 


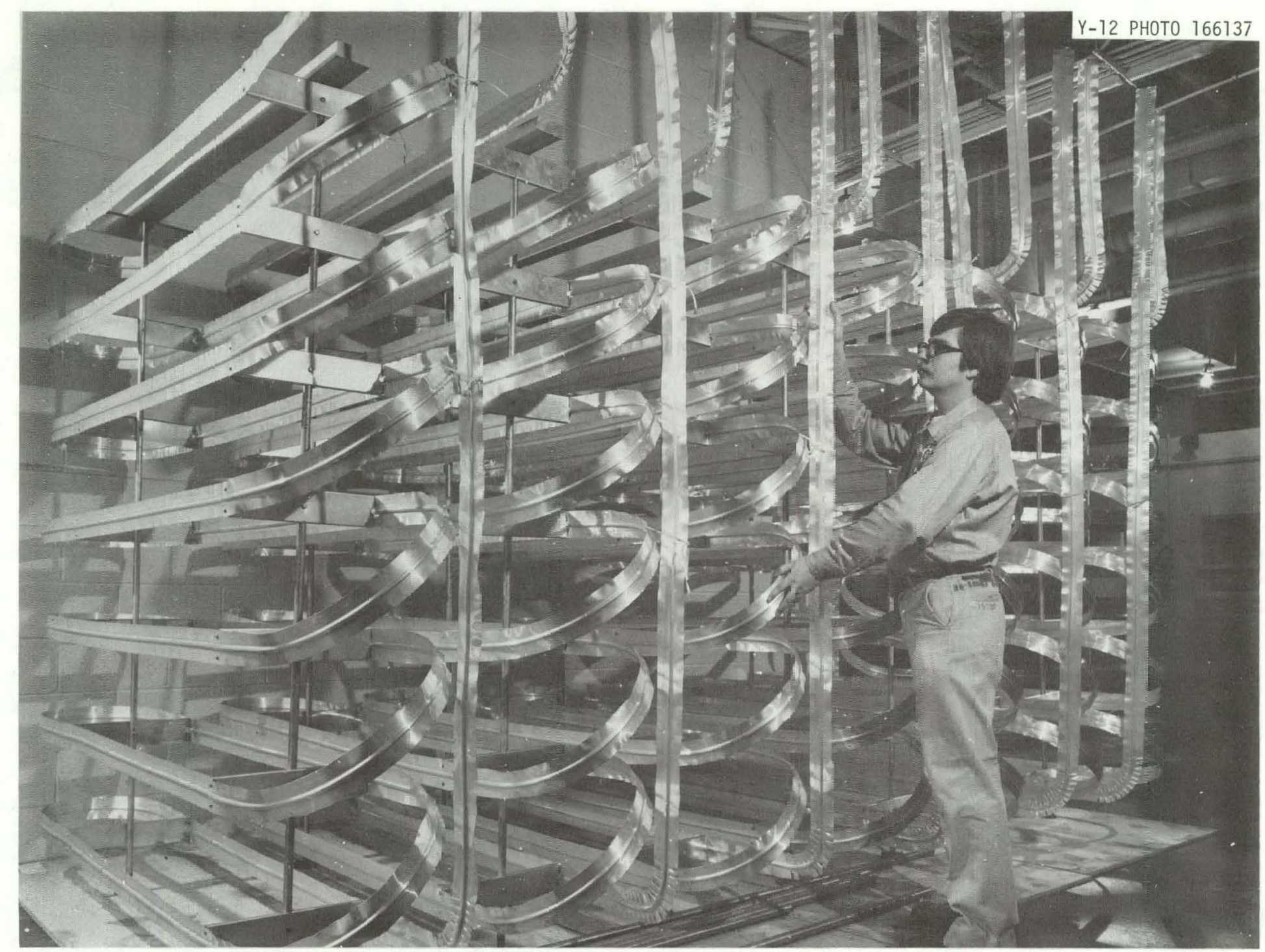

Fig. 3.5. Original ice-freezing coils. 


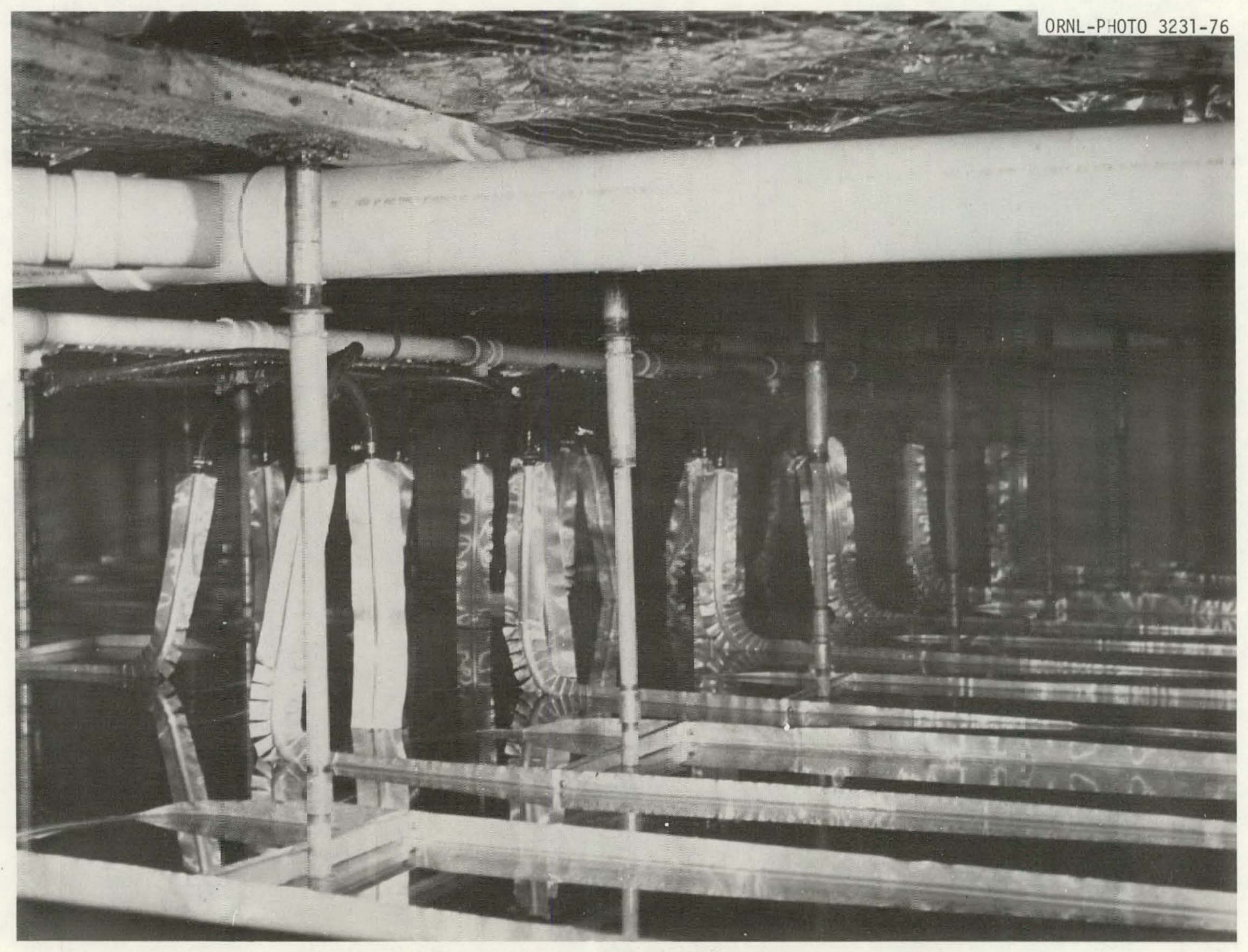

Fig. 3.6. Original ice-freezirg coils installet. 
After the brine system was made leaktight, filling of the bin was started. Once the water level reached the second course of Foam Form, however, a large leak occurred because of the cold joints in the Foam Form wal1s. These joints were caused by improper installation of the walls, as discussed in Sect. 3.1.1, and by improper application of the Nokorode coating used on the interior of the thermal storage bin. This coating was unable to adapt adequately to the irregular surfaces formed by the seams and chipped corners between the Foam Form blocks. Had the bin's interior surfaces been pargeted before applying the Nokorode, the material probably would have been satisfactory. In addition, proper installation of the Foam Form and Nokorode probably would have eliminated the leakage problem.

The various errors in the thermal storage bin construction necessitated some means of making the storage bin watertight. This means was a vinyl swimming pool liner, obtained and installed in the interior of the storage bin by a local swimming pool contractor. The liner proved satisfactory and no leaks in the storage bin have been observed since the liner's installation.

\subsubsection{ACES mechanical package}

During installation and checkout of the mechanical package, a large number of leaks were found in the brine circuit, but they posed no particular problem other than requiring repair. In addition to the leaks, a few errors were found in the power wiring and logic controls for the mechanical package.

The mechanical package for the ACES was designed to be a pump-down system, that is, a refrigerant system designed to prevent ingestion of slugs of liquid refrigerant into the compressor at startup. In a pumpdown system, after the refrigeration equipment has satisfied the load, the liquid refrigerant is not allowed to flow from the condenser to the evaporator, and the gas refrigerant remaining in the evaporator is pumped to the condenser by the compressor. When the equipment is needed later to satisfy another load, there is no liquid refrigerant in the evaporator to possibly slug the compressor. However, when the system was first 
installed, the pump-down feature failed to work reliably. This failure occurred because all brine flow to the heat exchangers was turned off after the house sensors were satisfied, leaving no place for the compressor to dump its excess heat during the pump-down process and causing the system to go out on high head pressure. This problem was corrected by changing the logic so that the domestic hot-water desuperheater is always active when the compressor is operating.

\subsection{ACES Operation}

The following sections pertain to the information gathered during the initial operation of the ACES. It was hoped that the first annual cycle would be run during the winter of 1976 and the spring, summer, and fall of 1977, but the aforementioned startup problems made this impossible. Therefore, this period was used to evaluate the short-term operational characteristics of the ACES and to make changes, as necessary, to improve its reliability and performance.

\subsubsection{Initial operating experiences}

During the initial startup procedures, the normal mechanical and electrical difficulties associated with most experimental systems were encountered. The majority of these problems centered on leaky joints, faulty components, and minor errors in design.

This initial startup process did point out the necessity for a domestic hot-water circuit correctly designed to deliver the highest temperature hot water at the lowest condensing temperature possible. For this to occur, the condenser and the desuperheater must be connected in a countercurrent manner with the water flow passing through the condenser before entering the desuperheater. In addition, the temperature control valve at the water exit from the desuperheater must bypass some small amount of water so that the water temperature leaving the desuperheater can be accurately sensed. The domestic hot-water storage tank must also be well stratified so that the coldest water possible will enter the hot-water condenser. This task can be accomplished by adding a diffuser lo the heated watcr inlet to the hot-water storage tank. 


\subsubsection{Fine tuning the ACES}

Some minor adjustments on the ACES were necessary to maximize its performance. Adjustments were made to the refrigerant charge and to the expansion valve in the refrigerant circuit, and experiments were run to determine where power inputs to components could be reduced.

This preliminary testing revealed that the pumps installed in the ACES had a wire-to-water efficiency of less than $10 \%$ under the imposed operation conditions. Because of the importance of pumping power to the performance of the ACES, a search was initiated to locate some highefficiency fractional-horsepower pumps. This search resulted in the installation of magnetic drive pumps having a wire-to-water efficiency of about $30 \%$ under the same operating conditions. Change to the highefficiency pumps reduced pumping power from $1.35 \mathrm{~kW}$ to $0.78 \mathrm{~kW}$, which raised the system COP from 2.24 to 2.64 in the space heating mode and from 2.92 to 3.07 in the domestic water heating mode.

\subsection{ACES Startup}

After fine tuning was completed, the system was placed on automatic operation. The only major mechanical problem encountered during this period, a warped diaphragm on one of the pumps, was caused by applying excessive pressure during the filling process for the brine circuit. This error required that a new pump be obtained and installed in the mechanical package.

\section{4 .1 Corrosion problems}

Although it was hoped that the ACES would operate in an annual cycle during this first year, this was not possible because of a major materials problem involving the extensive use of aluminum as the heat transfer surface in the ACES. Aluminum was selected because of its heat transfer characteristics, corrosion characteristics, and low cost. However, under certain circumstances, aluminum will corrode in a most dramatic fashion.

The ice-freezing coils were constructed from extruded aluminum finned tubing. To protect the aluminum, the water in the ice-and-water 
storage bin was maintained at a $\mathrm{pH}$ of 7.5 , and routine water samples were taken to determine if there was any chemical change in the water that might initiate corrosion. Although these analyses indicated that the aluminum coils were not being exposed to corrosive conditions, leaks developed in the ice-freezing coils in early January 1977. To determine the cause of the leaks, the ice-and-water storage bin was drained, and samples of the aluminum coil were analyzed by chemical and metallographic techniques. The analyses indicated that the failure was the classical pitting type of corrosion exhibited by aluminum. The cause of the pitting was determined to be biological, 5 and water analyses revealed relatively high concentrations of anaerobic bacteria in the storage bin. Had adequate steps been taken to prevent the growth of this anaerobic bacteria, it is believed that there would have been no corrosion problem.

Because the damage to the ice-freezing coils was widespread, replacing the aluminum ice-freezing coils with low-density polyethylene plastic coils was determined to be the best solution to the problem. The structural integrity of the coil structure had not been affected by the pitting, so the aluminum coils were used as the support structure for the plastic coils. The plastic coils were chosen after analysis indicated that the material change would cause little change in the average heat transfer characteristics of the ice-freezing coils because the ice itself is the major deterrent to heat transfer. The calculations indicated that there would be approximately a $1^{\circ} \mathrm{F}$ drop in the average evaporating temperature as a result of the change.

\subsubsection{Thermal storage bin problems}

Because the thermal storage bin was drained during this time, it was inspected to determine if there were any problems with the liner. This inspection revealed that the corners of the liner were severely stretched because thcy were rounded, the typical ronstruction for swimming pools, whereas the storage bin's corners were square. To alleviate this stress, vermiculite was pourcd into the corners to make them somewhat contoured.

In addition to this problem, there was and is a minor problem with the construction of the overhead supports in the storage bin. First, 
the ductwork for the heating and cooling system along with the sewage pipes runs through the bin, causing unnecessary penetrations of the bin wall, an unsightly appearance, and even greater problems if their repair ever becomes necessary. Secondly, because of the high relative humidity of the air over the thermal storage bin, deterioration of the wood supports has been noticed. Originally, humidity was not thought to be a problem because of the low moisture content of the air at $32^{\circ} \mathrm{F}$; however, because of the constant openings of the viewing window, the wood has remained constantly wet, thus causing the deterioration. Had the bin been better sealed, this problem would probably not exist.

\subsubsection{Mechanical package problems}

In addition to the corrosion of the ice-freezing coils, the aluminum tubes in the evaporator failed - twice before the problem was corrected. The cause of the first failure was never completely determined because of the difficulty in removing the evaporator for inspection. Instead, a second evaporator was obtained and mounted externally to the mechanical package. This evaporator also failed, and a careful examination revealed that the failure was the result of fretting between the tubes and the baffles. The evaporator was retubed with a copper-base material, and mixed metal inhibitors were added to the brine to protect against galvanic problems. Since these measures wcro taken, there have heen no further problems with the evaporator.

The ACES has been in continuous operation since May 1977, except during October when the new mechanical package was installed. Data are being gathered by an automatic data acquisition system (DAS), and Sect. 5 contains performance characteristics generated from these data. 


\section{NEW MECHANICAL PACKAGE}

After the initial problems with the first mechanical package were solved, the ACES operated steadily from May through August 1977. To improve reliability and appearance and to incorporate some new design features, a new mechanical package was designed and installed in the ACES demonstration house. The following sections discuss the design, installation, and checkout procedures followed during this undertaking.

\subsection{Package Design}

The decision was made in early March 1977 to design, procure, and install a new mechanical package. On the basis of the experience obtained during operation of the first package, five design goals were established: (1) improved reliability, (2) reduced noise and vibration levels, (3) improved performance, (4) simplified installation, and (5) improved appearance. In addition, components would be designed to allow for easy removal and replacement.

Figure 4.1 shows the refrigerant and brine schematics for the new mechanical package. As can be seen, the major components are isolated from each other by manual cutoff valves and unions, which allow any of the major components to be removed without disturbing the rest of the system or losing refrigerant charge. Also, pressure taps are provided around each of the major components so that the performance of individual components can be studied.

The schematics for the new package are almost identical to those of the old package. Indeed, both packages are capable of operating in all the same modes. The major difference between the two is the loop provided in the new package for either using or bypassing the suction line heat exchanger.

After selecting the new schematic, design conditions were established and the major components sized. Appendix B contains the complete list of design conditions and duties used to size the components. 


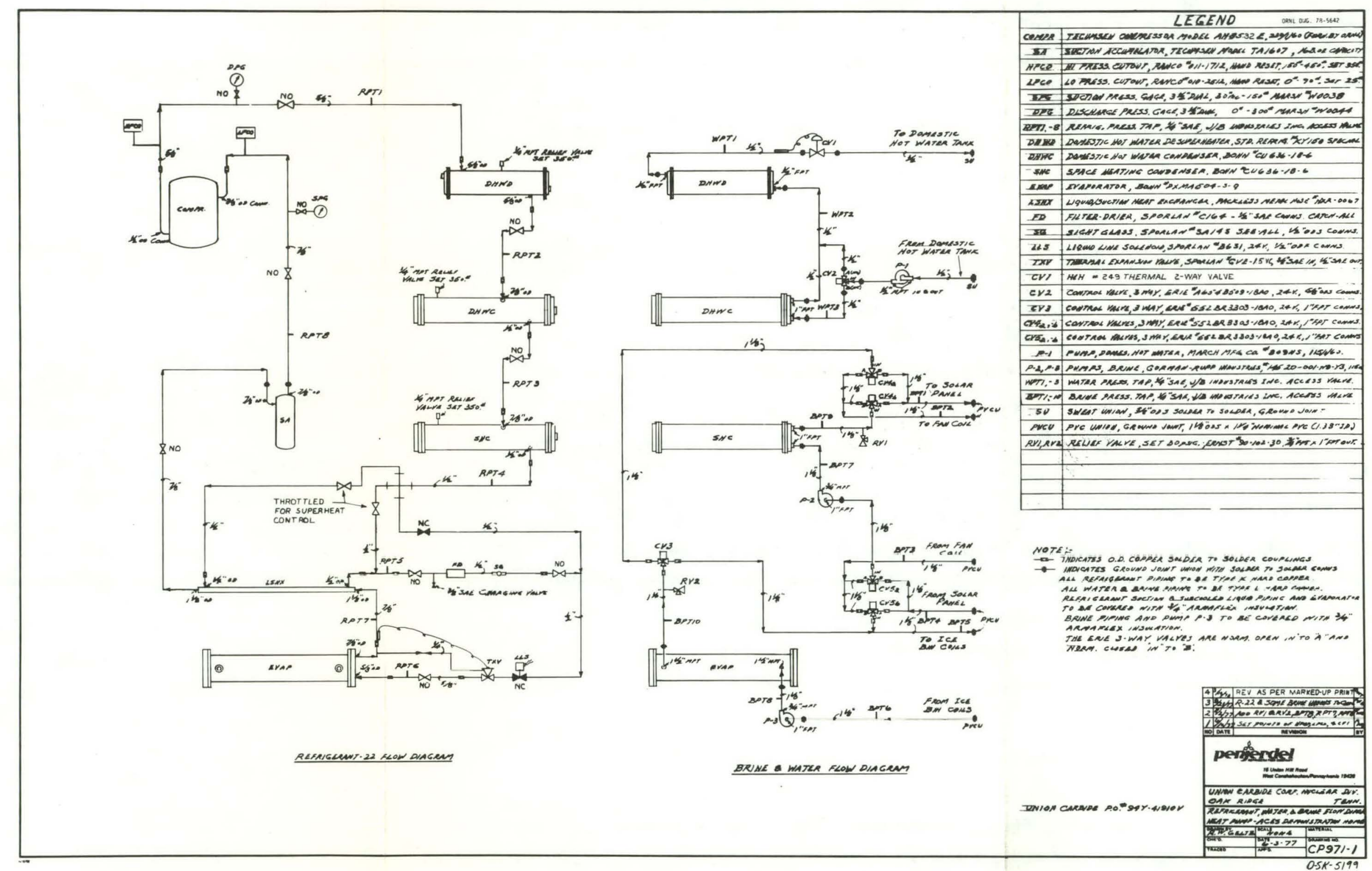

Fig. 4.1. Refrigerant and brine schematic. 


\subsection{Installation and Startup}

In May 1977 a contract was issued to Penjerdel Refrigeration Company of West Conshohocken, Pennsylvania, to provide the mechanical package layout and assembly. The new package was delivered in September 1977. The new design had taken into account ease of installation, which allowed the package to be installed quickly with the system ready for startup in early October.

During the initial startup period, some minor problems were encountered. When the system was pressure tested, a bad solder joint in a brine line was discovered and repaired. In addition, the condenser head gaskets extruded from the flanged joints and had to be replaced. These problems caused only a minor delay in testing the new package.

Testing of the package was required so that the superheat and refrigerant charge could be adjusted. During these tests, it was discovered that the expansion valve was undersized and had to be replaced. The importance of adjusting the refrigerant charge is shown in Fig. 4.2, which was obtained from experiments performed on an air-to-air heat pump by Domingorena. 6

The testing was completed and the system placed on automatic controls on October 31 , 1977, to begin the first full annual cycle test. The ACES has been in continuous operation since that time, and the DAS has been gathering performance data. The following sections provide discussions of the results obtained to date and predictions for the annual cycle based on these data. 


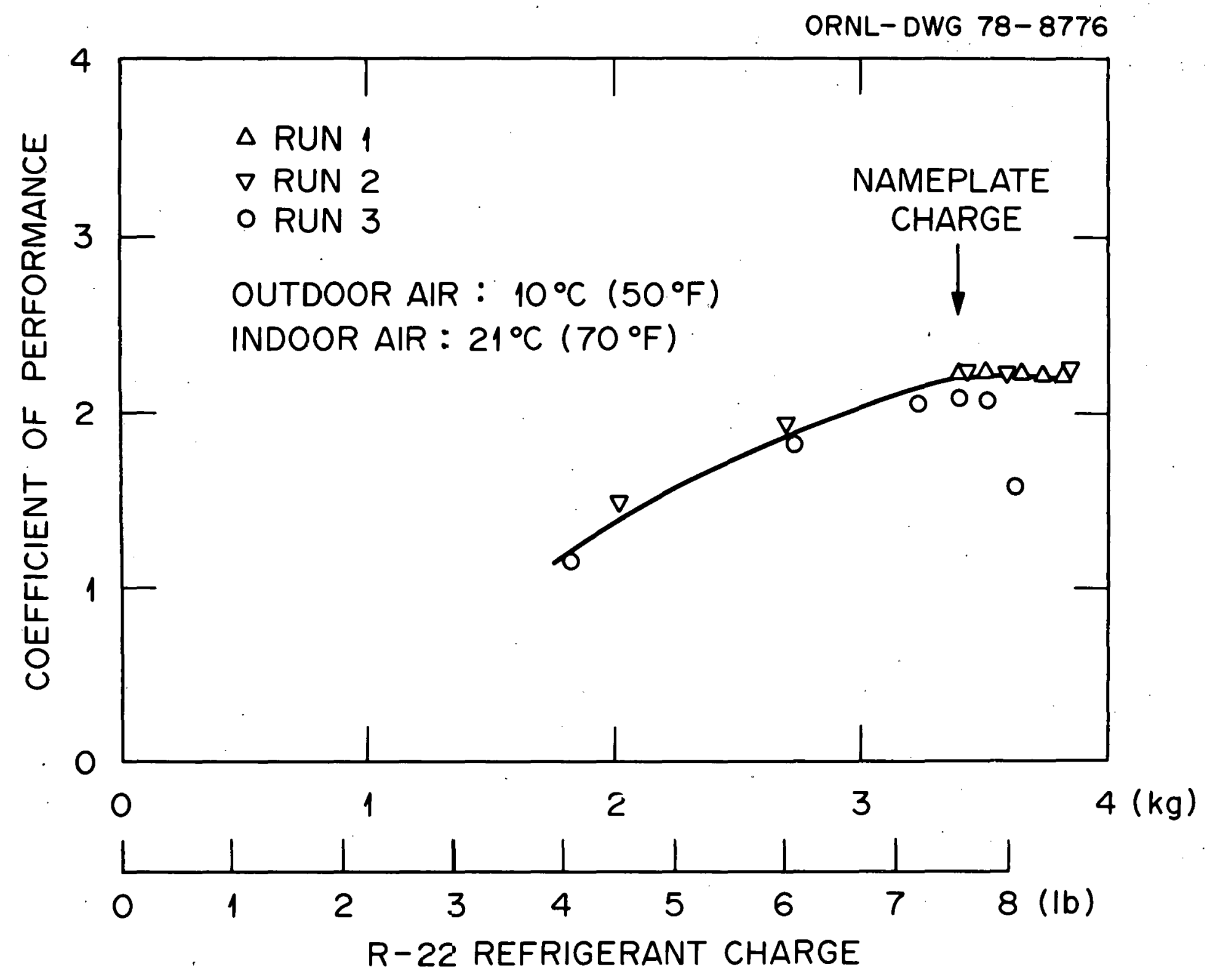

Fig. 4.2. COP as a function of refrigerant charge. 


\section{ACES PERFORMANCE}

The following sections present the performance data for the ACES demonstration house. Included are a discussion of the steady-state performance data gathered by the DAS located at the demonstration site, and a discussion of the winter performance results.

\subsection{Steady-State Performance}

The majority of the steady-state tests occurred during normal system operation. However, to obtain all essential data, it was

necessary to override the automatic controls so as to operate the system in the desired mode of operation. These data were gathered and analyzed during the period March through July 1977. Table 5.1 shows the measured performance data for the three primary modes of operation along with the performance for the balancing mode of night heat rejection. All steadystate performance measurements were made using the original mechanical package. 5

Table 5.1. Ful1-1oad performance

Function

Full-1oad COP

Space heating with water heating

2.65

Water heating only

Spacc cooling with stored ice

12.70

Space cooling with the storage $>32^{\circ} \mathrm{F}$ and $<45^{\circ} \mathrm{F}$

10.60

Night heat rejection with water heating ${ }^{\alpha}$

$0.50(2.50)$

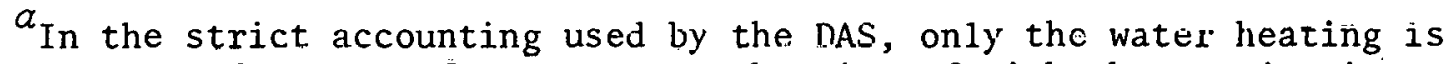
calculated as a useful output at the time of night heat rejection because credit is taken for the chilling when it is later used for space cooling. This procedure results in a COP. of 0.5 . If the chilling credit and the water-heating credit are taken at the time of operation, then a COP of 2.5 results.
} 


\subsection{Winter Performance}

The second mechanical package has been operating on a continuous basis since October 31, 1977. The DAS has been gathering performance data on the ACES and on the electric resistance heating and electric hot-water systems installed in the control house. The outside weather conditions and the inside conditions of both houses have also been monitored and recorded. Although the ACES provides the greatest energy saving over a full annual cycle, the data gathered during the winter's heating season show a significant saving during this period as well.

The system is, in essence, a fixed-capacity heat pump system. The ACES maintains its capacity because the evaporating temperature remains very nearly fixed throughout the heating season instead of varying with ambient conditions. The only factor that affects the evaporating temperature is the amount of ice on the freezing coils. Figure 5.1 shows the measured evaporating temperature as a function of the amount of ice present on the tubing. As can be seen, the evaporating temperature only varies from $28.0^{\circ} \mathrm{F}$ with no ice present to $25.5^{\circ} \mathrm{F}$ at maximum capacity.

\section{$5.2: 1$ Winter energy usage}

Table 5.2 sliuws the mcasured and predicted energy consumptions for three different systems to provide the heating load required. These three systems are (1) electric resistance heating and electric hot-water heatcr, (2) heat pump heating with electric hot-water heater, and (3) ACES. The loads shown in Table 5.2 are those actually incurred by the ACES from October 31, 1977, through March 26, 1978. The energy consumed by the all-electric system was calculated by assuming a COP of 1 , whereas the energy consumption of the heat pump system was calculated by assuming an average COP of 2.1 for heating and 1 for hot water. The energy consumed by the ACES was that actually measured by the DAS.

During its first winter of operation, the ACES has demonstrated significant energy savings over both electric resistance heating and the estimated performance of heat pump systems. These savings are a direct result of the fixed-capacity nature of the ACES and its high COP. Figure 5.2 shows that the COP for ACES remained at a constant 2.77 even though 


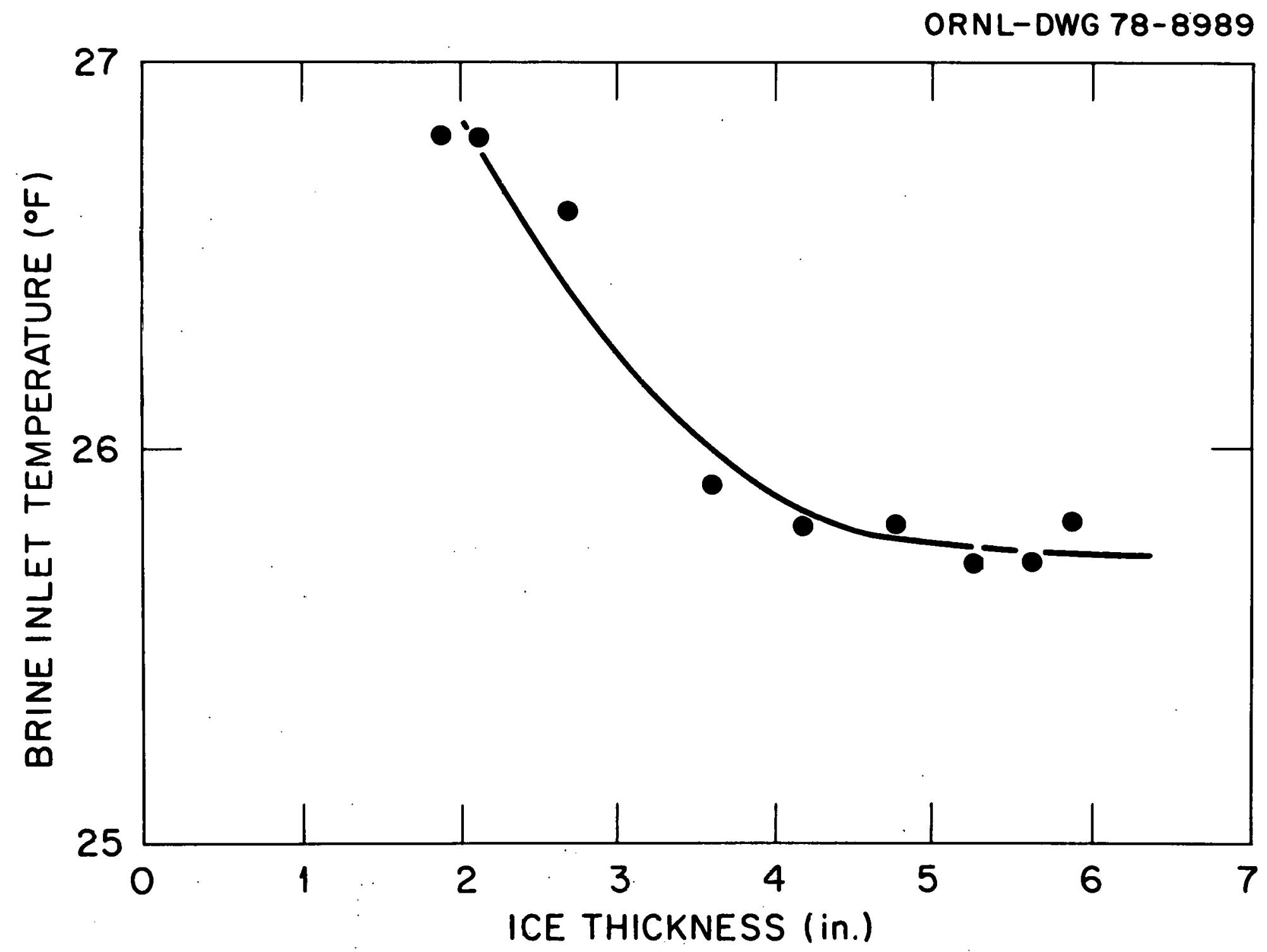

Fig. 5.1. Evaporator temperature as a function of ice on the tubing. 


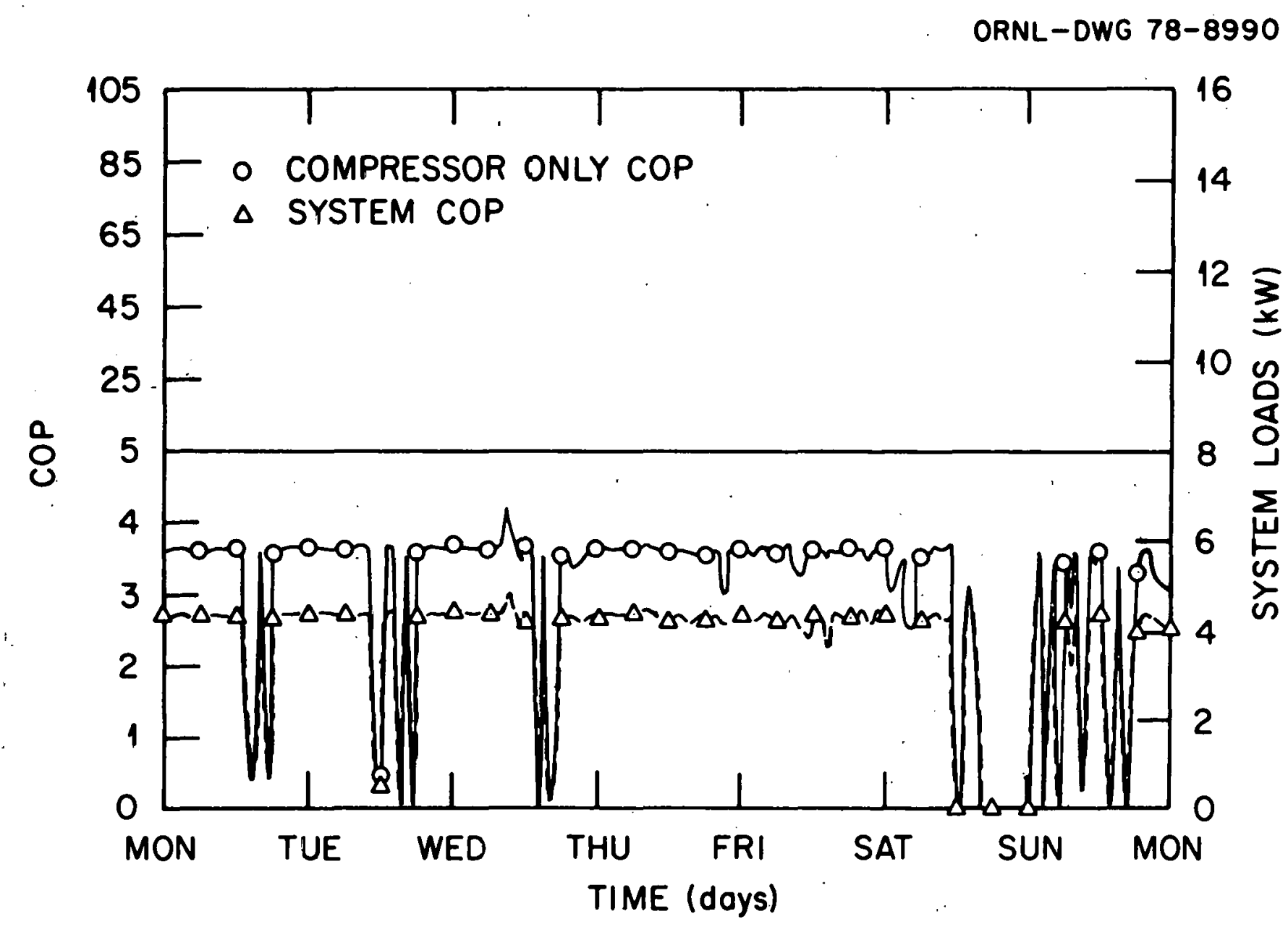

Fig. 5.2. ACES performance analysis, week beginning January 2, 1978. 
Table 5.2. Actual space- and water-heating energy requirements ${ }^{a}$

\begin{tabular}{|c|c|c|c|c|}
\hline & $\begin{array}{c}\text { Load } \\
(\mathrm{kWh} r)\end{array}$ & $\begin{array}{l}\text { ACES } \\
\text { consumption } \\
(\mathrm{kWhr})\end{array}$ & $\begin{array}{c}\text { Elec. furnace, } \\
\text { elec. water heater } \\
\text { consumption } \\
(\mathrm{kWh})\end{array}$ & $\begin{array}{l}\text { Heat pump, } \\
\text { elec. water heater } \\
\text { consumption } \\
(\mathrm{kWh} r)\end{array}$ \\
\hline Heating & 10,546 & \multirow{2}{*}{4960} & 10,546 & 5021 \\
\hline Hot water & 2,657 & & 2,657 & 2657 \\
\hline TOTAL & 13,203 & 4960 & 13,203 & 7678 \\
\hline
\end{tabular}

${ }^{a}$ Covers period from October 31, 1977, through March 26, 1978.

the outside temperature dropped to a low of $-1^{\circ} \mathrm{F}$. During this same week, a conventional heat pump would have operated using a large amount of resistance heat, thereby dropping its COP closer to 1 .

Table 5.2 indicates that the ACES has consumed $62 \%$ less energy than the all-electric system and $35 \%$ less energy than the estimated requirement for a heat pump system.

\subsubsection{Winter load profile}

The ACES, because of its fixed capacity and high COP, presents a much-improved load profile over conventional electric heating systems. Although its load curve is nearly identical to that for single-stage electric resistance heating, the ACES maintains a COP of 2.77 and thereby greatly reduces the magnitude of the energy consumpliun. An air-to-air heat pump, which also operates at a COP greater than 1 under most conditions, has the undesirable trait of a decreasing COP with decreasing outdoor dry bulb temperature. This characteristic forces the heat pump system to require supplemental resistance heating during periods of maximum load, thus increasing the utility's peak load when it can least afford it. In addition, an improved load profile of the ACES occurs because of the method of producing hot water whenever heating is called for. Hot water is preheated to temperatures well above the thermostat setting before it is used, thereby retaining extra heat in the storage tank. When the hot water is used the follnwing morning, it is not 
necessary to reheat the water immediately because an excess of hot water has already been produced. Thus, the ACES offers additional peak reduction because the hot-water heating requirements are not added to the other early morning requirements for electricity.

Figure 5.3 shows the hourly consumption of electricity for both the ACES and the all-electric system during a cold week. Because of the unusually cold weather faced during this week, the electric consumption of a conventional heat pump system would have looked very similar to that of the all-electric system. The plot shows that the ACES reduced the peak power demand from 13 to $3.1 \mathrm{kWhr}$, resulting in a $76 \%$ peak power reduction at 8:00 AM, the most critical time for the utility.

The ACES produces this peak reduction by maintaining its high COP and by making hot water whenever heating is called for. The high COP accounts for $64 \%$ of the peak reduction while the other $12 \%$ comes from the off-peak hot water production. Although an electric hot-water system can be operated to produce hot water off peak, this is not normally done. The ACES, on the other hand, produces hot water off peak whenever space heating is required.

\section{2 .3 Winter bin performance}

The therillal storago bin began the annual cycle with no ice present. Heat has been extracted from the bin to provide space heating and domestic hot water since October 31, 1977, and as of March 26, 1978, it contained 57 tons of ice. Because the tank actually entered the annual cycle at a temperature greater than $32^{\circ} \mathrm{F}$, it was December 19,1977 , before ice started forming on the coils.

Figure 5.4 shows the ice inventory as a function of time for the present heating season. The ice bin is considered to be full when it contains 59 tons of ice. This amount of ice is presently estimated to last until sometime in August 1978, meaning that some portion of the cooling requirement will have to be met using night heat rejection. 


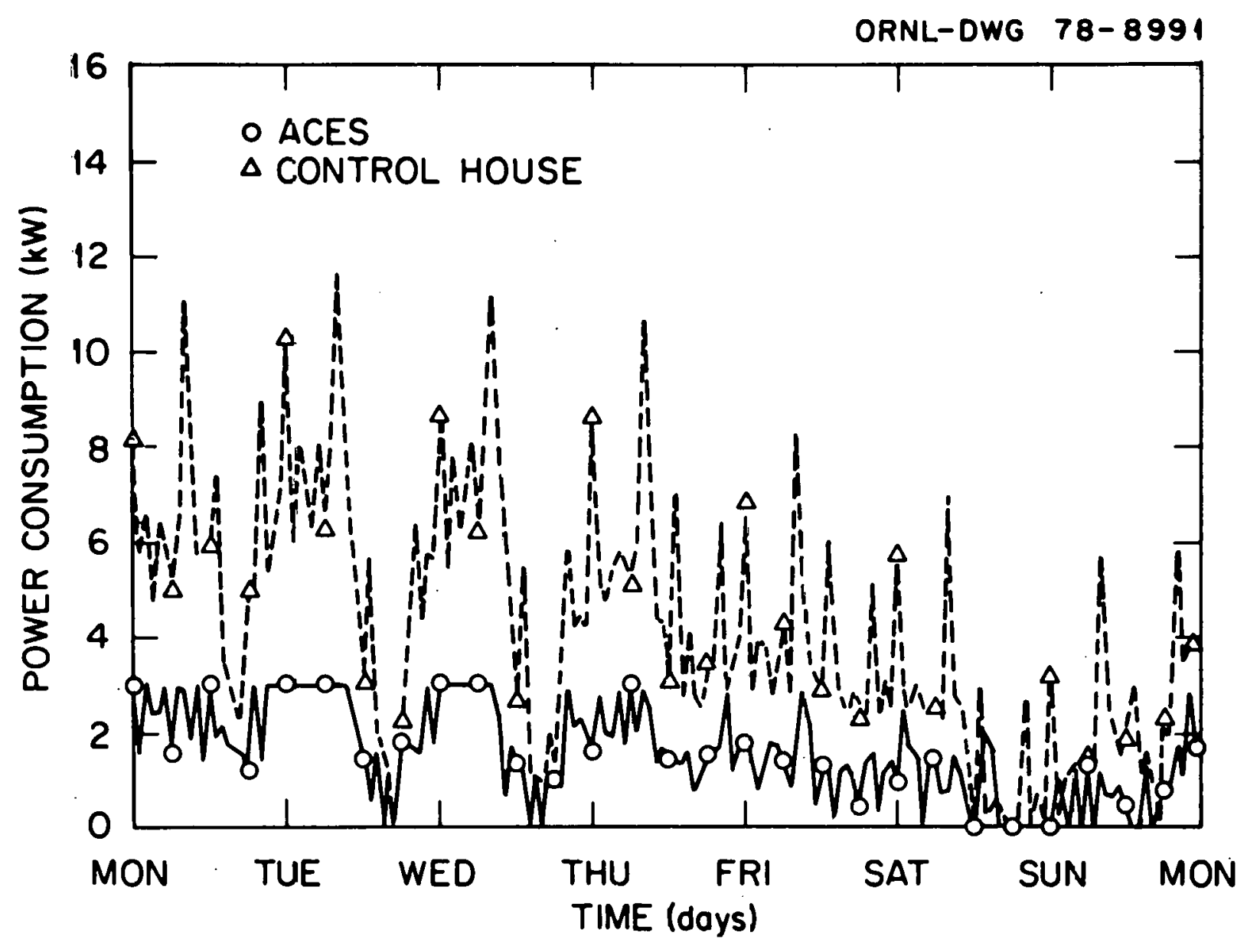

Fig. 5.3. Comparison of ACES and control houses, week beginning January 2, 1978. 


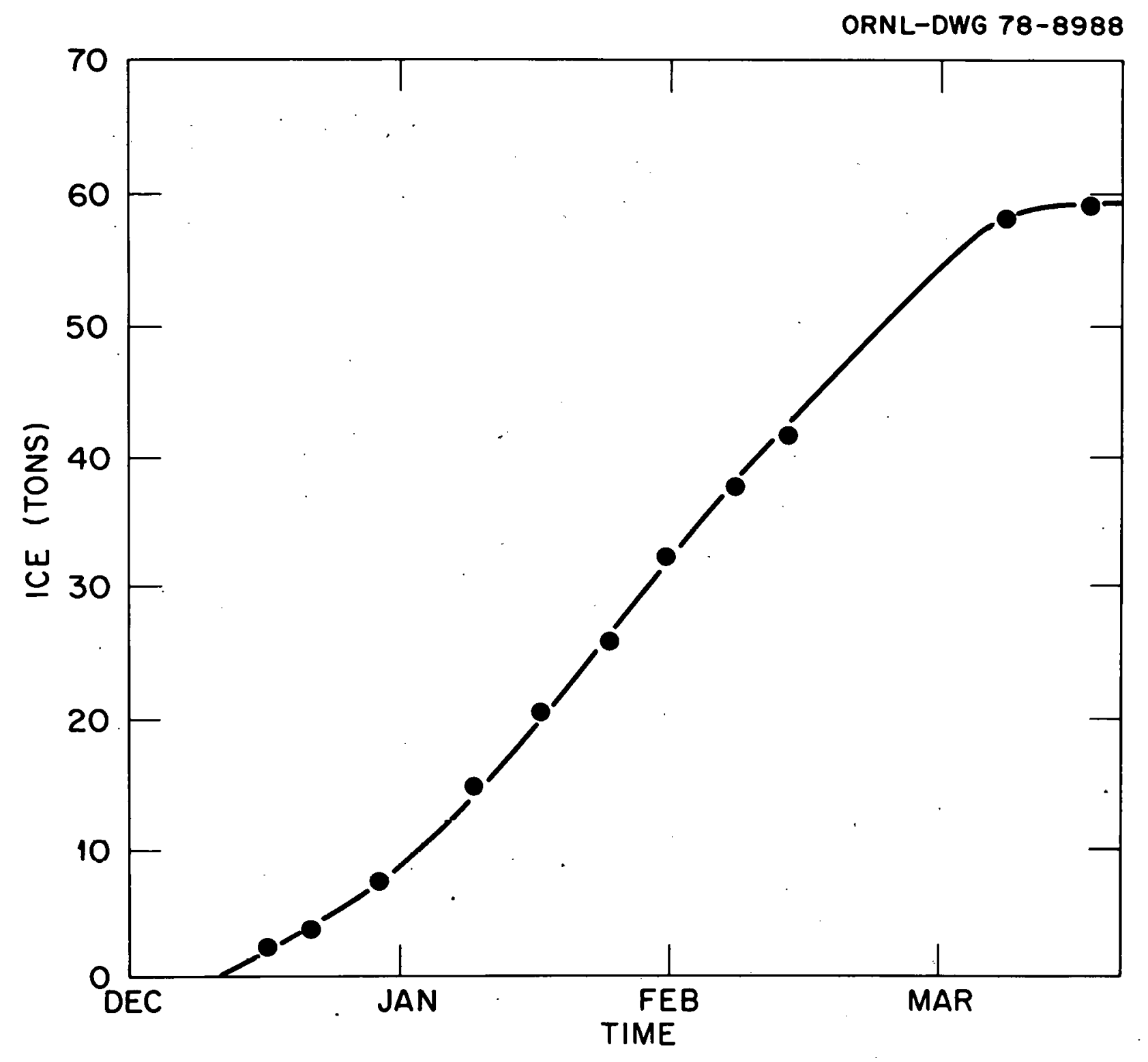

Fig. 5.4. Ice inventory as a function of time. 


\subsection{Summer Performance}

Although the ACES has not yet operated during a summer cooling season using stored ice to provide the space cooling requirements, its performance can be predicted. The following sections present data obtained during the summer of 1977 with the ACES both operating on stored ice and using the night heat rejection mode to generate space cooling during off-peak hours.

\subsubsection{Summer energy usage}

The energy requirements for the ACES to provide space cooling when operating from stored ice are only the power input to one pump and the fan. This is, of course, much less than that required to operate the compressor and fans as a conventional cooling system must do. The ACES has a COP of 13 when operating in this mode as compared to a COP of about 2 for the conventional heat pump, which results in an $85 \%$ energy saving over the air-to-air heat pump. The ACES load curve is also improved because, even though it has the same pattern, the magnitude has been greatly reduced.

\subsubsection{Summer load management}

Because of the difficulties encountered during the winter of 1976-1977, the ACES entered the 1977 summer cooling season with very little stored ice. Consequently, the system had to deliver the majority of the cooling load using the night heat rejection mode of operation. In this mode, the system operates during the off-peak night hours to produce ice for future use in providing space cooling. Figure 5.5 shows a typical week in which this mode occurred. As can be seen, the ACES energy consumption is $180^{\circ}$ out of phase with that for the conventional air-to-air heat pump in the control house. This mode of operation does not result in much, if any, energy savings; however, it does result in significant peakload reductions to the utility. Energy savings result from this mode of operation because night heat rejection produces the domestic hot water as a by-product. 


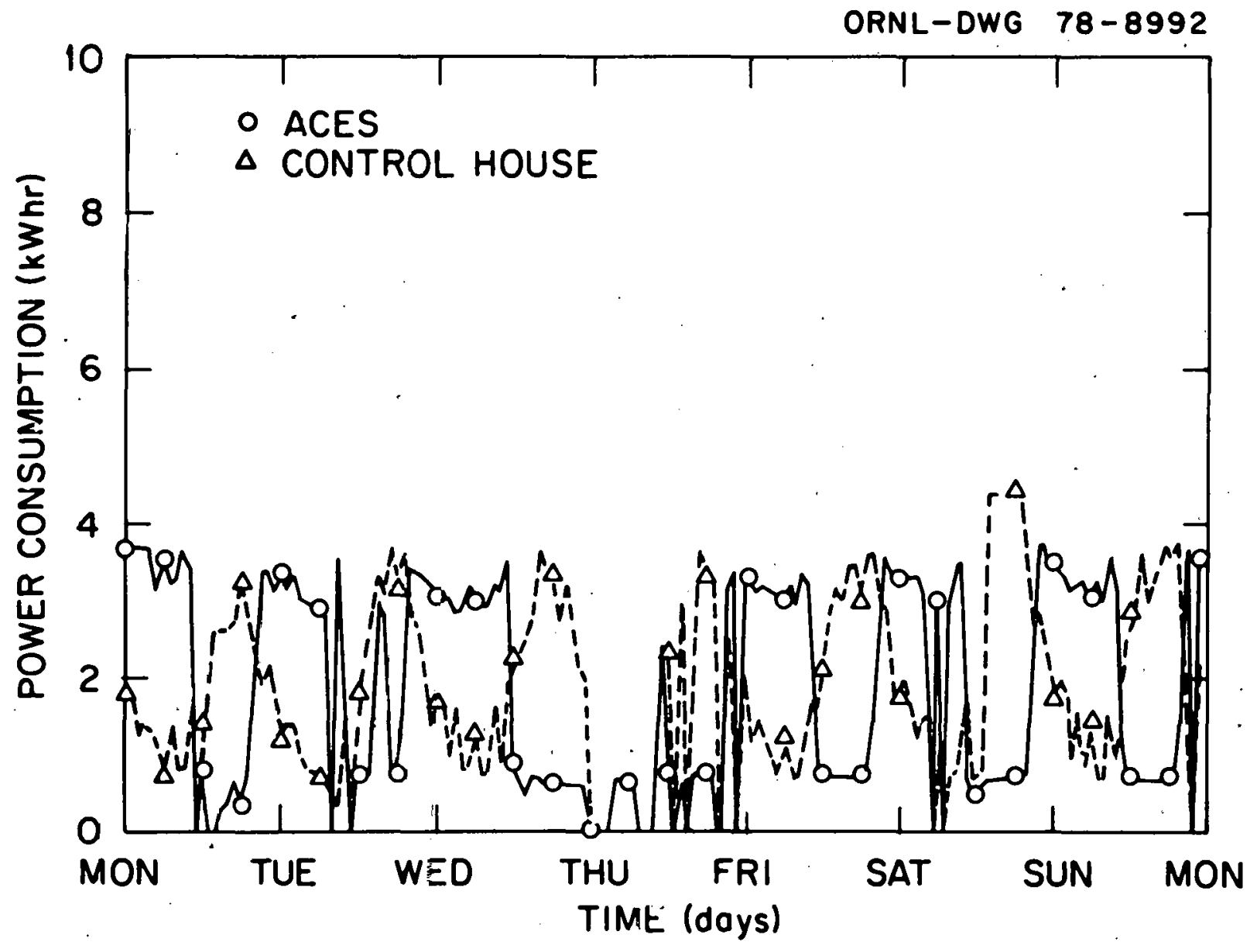

Fig. 5.5. Comparison of ACES and control houses, week beginning August 1, 1977. 
APPENDTCES 
THIS PAGE

\section{WAS INTENTIONALLY \\ LEFT BLANK}


Appendix A

COMPONENT SPECIFICATIONS AND DESIGN DATA

1. GENERAL

The following information is as presented in the Design Report for the ACES Demonstration House, ${ }^{1}$ except where later field changes were made as noted.

The mechanical installation isometric, Fig. A.l, indicates the location and relative size of the components and the routing of the piping.

\section{ICE STORAGE TANK}

The ice storage tank is constructed as an integral part of the basement-foundation of the house. The floor slab and footings are a continuous pour (no expansion joint). Poured into the footings are vertical reinforcing bar stubs, a $2 \times 4$ in. key to tie the vertical walls, and a $1 \times 4$ in: rubber water stop. The walls are a reinforced concrete monolith poured in Foam Form. The floor and walls are finish coated with an asphalt-urethane preparation (Lion 0il Nokorode 705), primarily to prevent chemical interaction between the concrete and water and as an added waterproofing. The top or cover is the floor above, with 12-in. fiberglass batts between the floor joists:

$\begin{array}{ll}\text { Dimensions } & \begin{array}{c}19 \times 17.5 \times 7.5 \mathrm{ft} \text { fill level } \\ \left(2500 \mathrm{ft}^{3}\right)\end{array} \\ \begin{array}{l}\text { Maximum permissible ice } \\ \text { inventory }\end{array} & 2000 \mathrm{ft}^{3} \\ \begin{array}{l}\text { Total heat of fusion } \\ \text { available }\end{array} & 16.5 \times 10^{6} \mathrm{Btu} \\ \begin{array}{l}\text { Sensible heat between } 45 \\ \text { and } 32^{\circ} \mathrm{F}\end{array} & 2.1 \times 10^{6} \mathrm{Btu} \\ \begin{array}{l}\text { Average daily cooling load } \\ \text { range }\end{array} & 100,000-250,000 \mathrm{Btu} \text { per day }\end{array}$


ORNL-OWG 76-8807

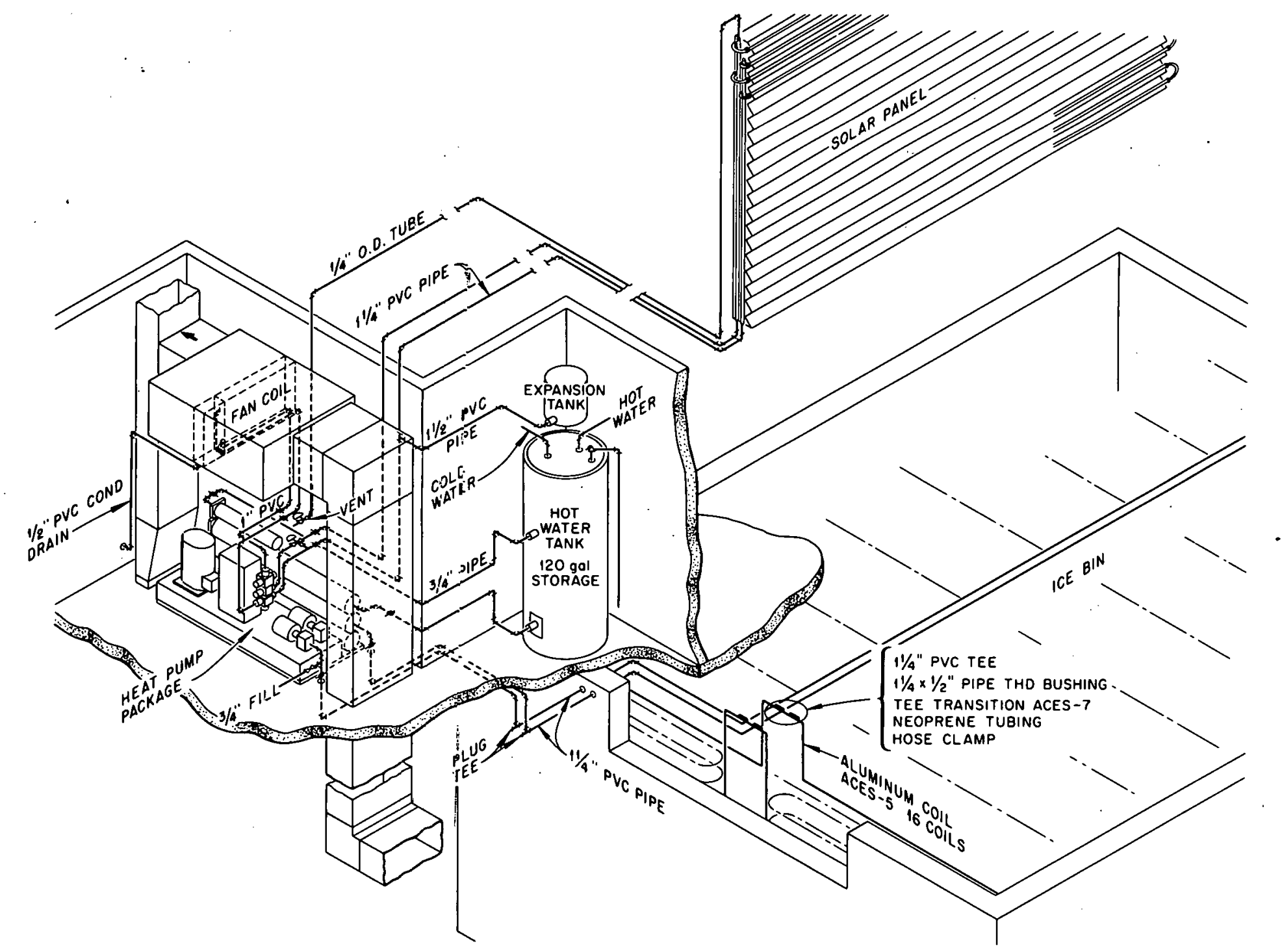

Fig. A.1. System isometric. 


\section{ICE BUILDING COILS}

The coils are constructed of an extruded aluminum tube (Fig. A.2) having an outside diameter of $1 / 2$ in. and an integral axial fin with an overall width of 3 in. The tubing is mounted on support structures that extend from the tank floor to the floor joists overhead to support the weight or resist the buoyancy as the case may be.

$\begin{array}{ll}\text { Tubing quantity } & 1950 \mathrm{ft} \\ \text { Number of parallel circuits } & 16 \\ \text { Center distance } & 13 \mathrm{in} . \\ \text { Maximum permitted ice diameter } & 13 \mathrm{in} . \\ \text { Thermal loading } & 12 \mathrm{Btu} / \mathrm{ft} \cdot \mathrm{hr} \\ \begin{array}{l}\text { Brine-to-water } \Delta \mathrm{T} \text { at maximum } \\ \text { ice diameter }\end{array} & 9^{\circ} \mathrm{F}\end{array}$

In November 1976, the aluminum tubing suffered a number of perforation failures induced by microbiological action and was replaced by 1 -in. $-O D \times 0.093$-in.-wall low-density polyethylene tubing. The design calculations for this tubing predicted about a $1^{\circ} \mathrm{F}$ greater brine-to-water $\Delta \mathrm{T}$. No change in performance has been observable.

\section{RADIANT/CONVECTOR PANEL}

The radiant/convector panel occupies a south-facing vertical break in the roof about $8 \mathrm{ft}$ high $\times 34 \mathrm{ft}$ long (Fig. 2.4). The tubing is that shown in Fig. A.2. The support members are $2 \times 6 \mathrm{in}$. wood studs cut to a sawtooth form to orient each tube fin $30^{\circ}$ from the vertical (normal to the noon sun at winter solstice) and separate them vertically to prevent shadowing. The tubes are nailed to the studs through the fins. The supply and return headers are at one end and return bends at the other to form 13 parallel circuits. No glazing or insulation is installed, and free convective airflow is permitted through the panel. The tubes are painted a flat brown. 


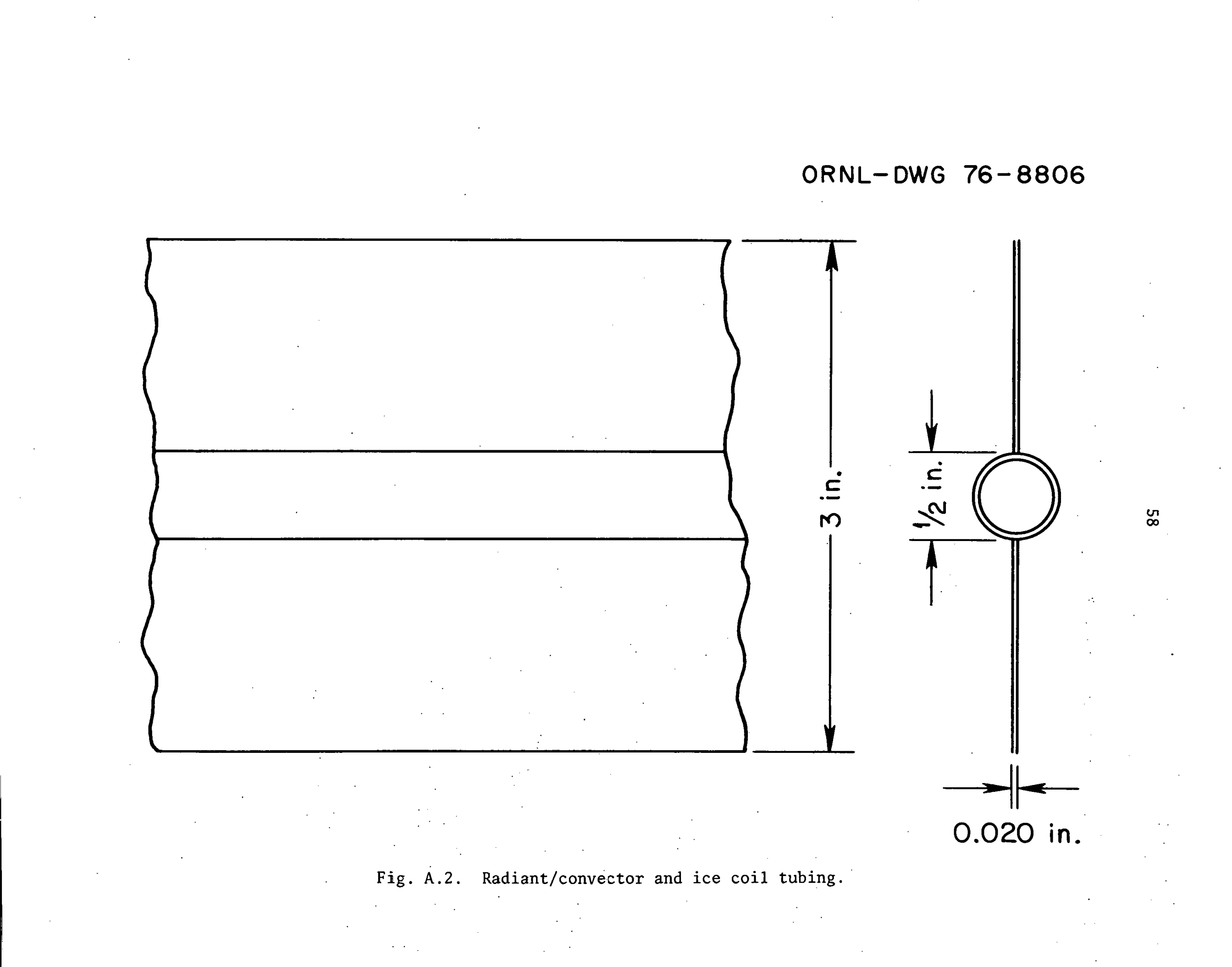




$\begin{array}{ll}\text { Number of tubes } & 26 \\ \text { Length of tubes } & 32 \mathrm{ft} \\ \text { Radiant surface area } & 208 \mathrm{ft}^{2} \\ \text { Convective surface area } & 415 \mathrm{ft}^{2} \\ \text { Design convective coefficient } & 2 \mathrm{Btu} / \mathrm{ft}^{2} \cdot \mathrm{hr}^{\circ}{ }^{\circ} \mathrm{F} \\ \text { Average incident solar energy } & 9000 \mathrm{Btu} / \mathrm{ft}^{2} \cdot \text { week } \\ \text { Dec. 15-Feb. 15 } & 240 \mathrm{Btu} / \mathrm{ft}^{2} \cdot \text { week } \\ \text { Average convective energy } & 9480 \mathrm{Btu} / \mathrm{ft}{ }^{2} \cdot \text { week, or } 2 \times 10^{6} \\ \text { Dec. 15-Feb. 15 } & \mathrm{Btu} / \mathrm{week} \text { for the whole pane1 } \\ \text { Average total available energy } & \begin{array}{l}\text { Dec. 15-Feb. 15 } \\ \text { Average house requirement }\end{array}\end{array}$

\section{FAN COIL}

The fan coil unit located in the main air duct contains the finned tube brine coil, the circulating air blower, and the motorized damper. for the ventilation cycle.

$\begin{array}{ll}\text { Face area } & 2.5 \mathrm{ft}^{2} \\ \text { Number of rows } & 6 \\ \text { Liquid-side pressure drop } & 6 \mathrm{ft} \mathrm{H}_{2} \mathrm{O} \\ \text { Liquid flow } & 6-8 \mathrm{gpm} \\ \text { Airflow } & 1200 \mathrm{ft}^{3} \\ \text { Air-side pressure drop } & 0.25 \mathrm{in} . \mathrm{H}_{2} \mathrm{O}\end{array}$

\section{BRINE}

The circulating brine is $20 \%$ methanol and $80 \%$ water.

Freezing point

Boiling point

Density

Specific heat $4.5^{\circ} \mathrm{F}$

$182^{\circ} \mathrm{F}$

$60.4 \mathrm{lb} / \mathrm{ft}^{3}$

$0.97 \mathrm{Btu} / 1 \mathrm{~b} \cdot{ }^{\circ} \mathrm{F}$ 
THIS PAGE

\section{WAS INTENTIONALLY \\ LEFT BLANK}


Appendix B

MECHANICAL PACKAGE DESIGN SPECIFICATIONS

The following sections contain the specifications for the new mechanical package. The last section contains the final drawings for the package as built.

\section{Compressor}

a. The refrigerant compressor shall be Tecumseh Mode1 \#AH8532E, R-22, with a capacity of $250-260 \mathrm{lb} / \mathrm{hr}$ at $20^{\circ} \mathrm{F}$ (saturated) evaporating temperature and $110^{\circ} \mathrm{F}$ (saturated) condensing temperature.

b. The compressor electric circuit shall be provided with a starting capacitor, sized to permit the compressor to start against a nonequalized, no pump-down system at a differential of $226 \mathrm{psig}\left(110^{\circ} \mathrm{F}\right)$ to $41 \mathrm{psig}\left(20^{\circ} \mathrm{F}\right)$.

\section{Domestic Hot-Water Desuperheater}

a. The capacity of the desuperheater is $6000 \mathrm{Btu} / \mathrm{hr}$ when heating domestic hot water entering at $55^{\circ} \mathrm{F}$, at a flow of $4 \mathrm{gpm}$, and with the desuperheating compressor discharge entering at $226 \mathrm{psig}$ $\left(230^{\circ} \mathrm{F}\right)$ and leaving as a desuperheated vapor at not less than $111^{\circ} \mathrm{F}$.

b. The domestic-water-side pressure drop through the desuperheater shall not exceed 1 psi at a flow rate of 4 gpm.

c. The desuperheater should be arranged for countercurrent flow. (Valve CV1, shown in Fig. B.1, will control the flow of domestic hot water through the desuperheater so as to regulate its discharge temperature at $120^{\circ} \mathrm{F}$.) 


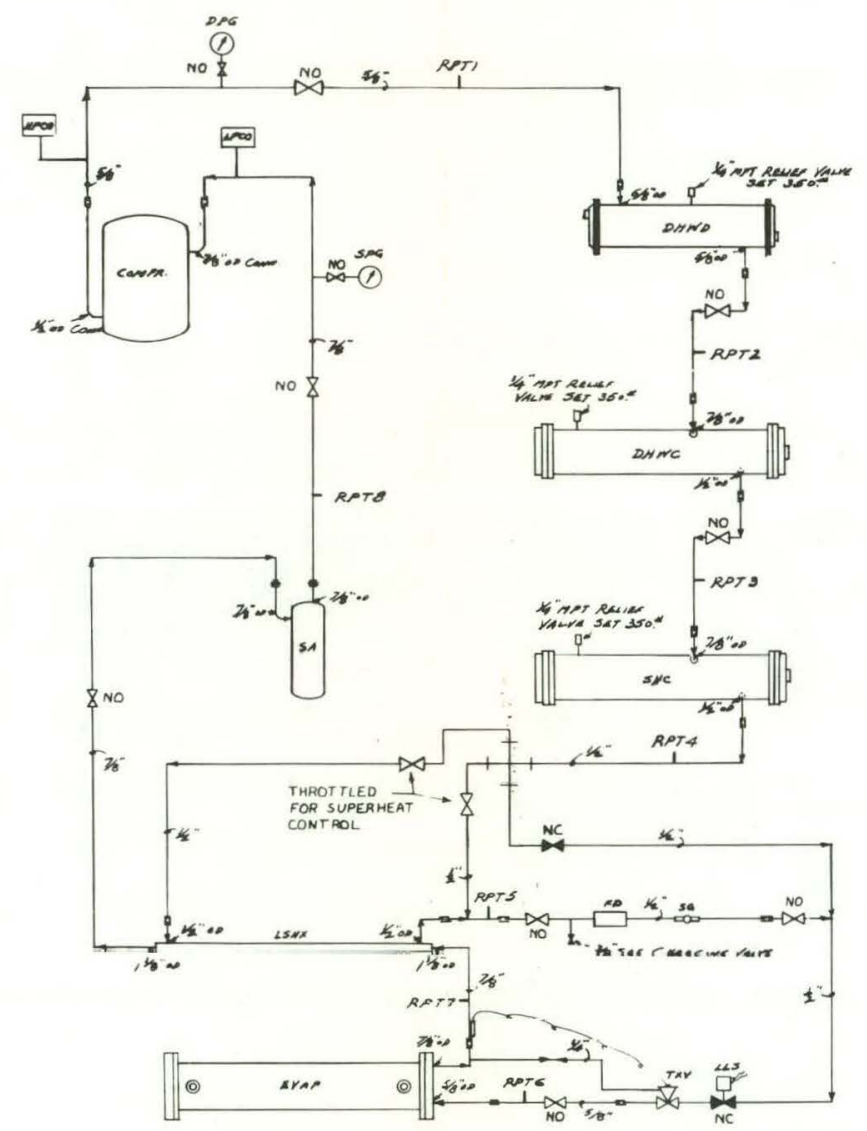

REsRGGewT-22 ELOW DIAGen

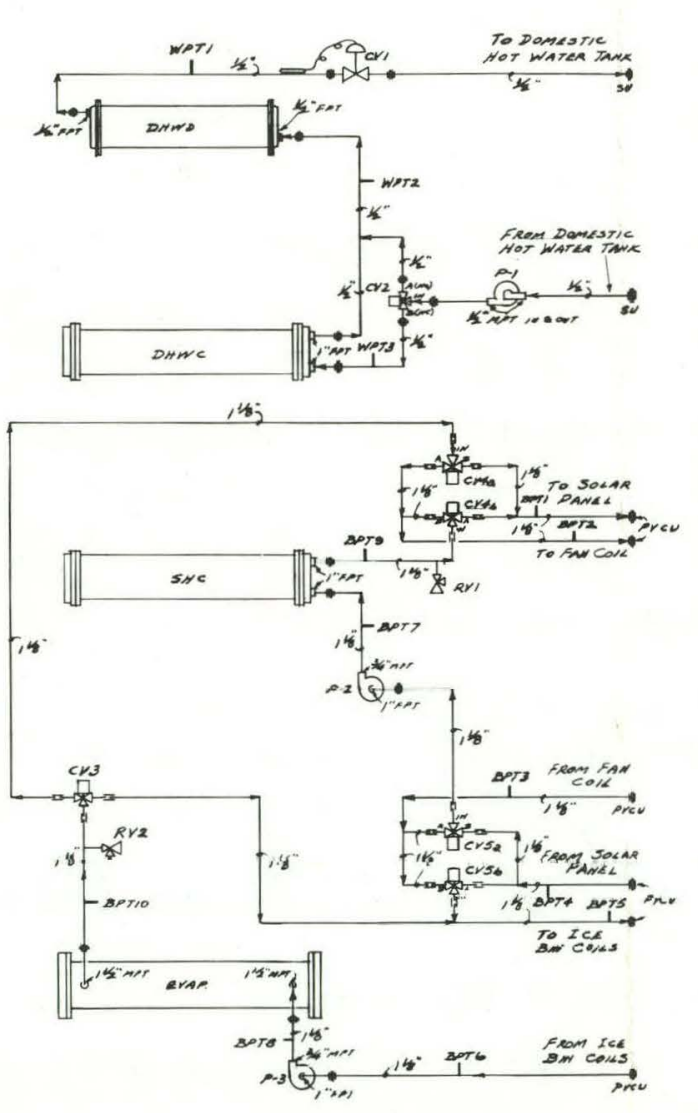

BRNA \& WATER FLOW DIACEM
LEGEND

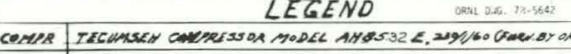

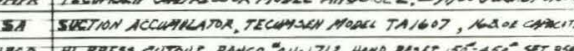

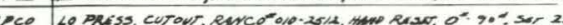

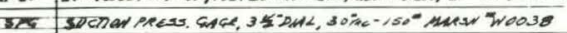

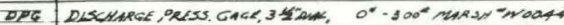

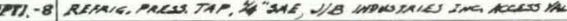

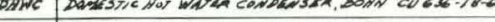

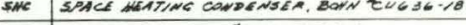

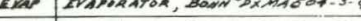

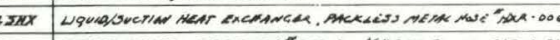

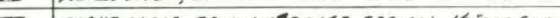
ULS $T$ TVI EVI HEH $=249$ THERMAL 2-WAY VALVE

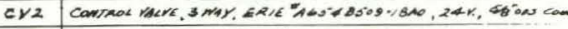

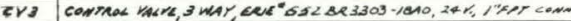

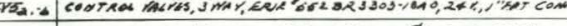

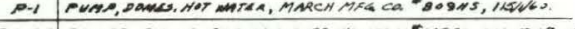

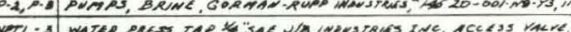
upi

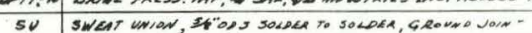

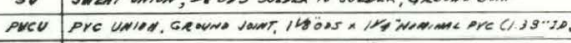

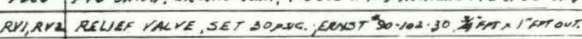

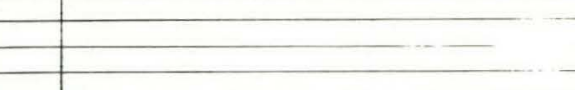

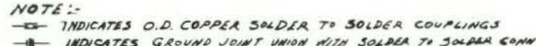

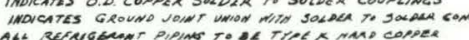

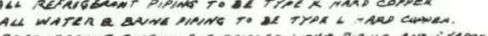

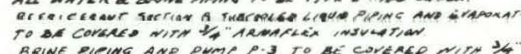

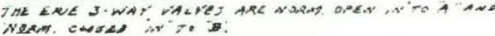

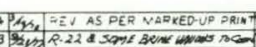

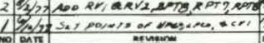
perperchel

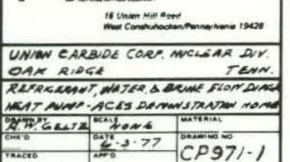

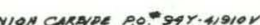

Fig. B.1. Refrigerant, water, and brine flow diagram. 


\section{Domestic Hot-Water Condenser}

a. The capacity of the condenser is $18,500 \mathrm{Btu} / \mathrm{hr}$ when heating domestic hot water entering at $55^{\circ} \mathrm{F}$, at a flow rate of $4 \mathrm{gpm}$, and with the condensing compressor discharge refrigerant (entering from desuperheater) from $226 \mathrm{psig}\left(111^{\circ} \mathrm{F}\right)$ to 226 psig $\left(100^{\circ} \mathrm{F}\right)$.

b. The domestic-water-side pressure drop through the domestic hot-water condenser shall not exceed 1 psi at a flow rate of $4 \mathrm{gpm}$.

c. The domestic hot-water condenser should be arranged for countercurrent flow. (Valve CV2, Fig. B.1, will bypass the domestic water flow around the domestic hot-water condenser when the space heating condenser is operational. However, it will divert this flow through the domestic hot-water condenser whenever the space heating condenser is not operational but when the compressor is required for domestic hot-water heating only.)

\section{Space Heating Condenser}

a. Duty:

(1) (When the domestic hot-water desuperheater is at a capacity of $6000 \mathrm{Btu} / \mathrm{hr}$ )

(a) $18,500 \mathrm{Btu} / \mathrm{hr}$ when heating $8 \mathrm{gpm}$ methanol and water (25\% methano1 by weight) from 97.23 to $102.36^{\circ} \mathrm{F}$ when condensing R-22 refrigerant entering at 226 psig $\left(111^{\circ} \mathrm{F}\right)$.

(2) (When the domestic hot-water desuperheater is not in operation) 
(a) 24,500 Btu/hr when heating $8 \mathrm{gpm}$ methanol and water (25\% methanol by weight) from 97.23 to $104^{\circ} \mathrm{F}$ when condensing R-22 refrigerant entering at 226 psig $\left(230^{\circ} \mathrm{F}\right)$.

b. The methanol-solution-side pressure drop shall not exceed 2 psi at a flow rate of $8 \mathrm{gpm}$. The refrigerant-methanol solution flow should be arranged for countercurrent flow.

5. Evaporator (Methanol Brine Cooler)

a. The evaporator's capacity is $17,500 \mathrm{Btu} / \mathrm{hr}$ when cooling $20 \mathrm{gpm}$ of methanol and water (25\% methanol by weight) from 26.45 to $24.55^{\circ} \mathrm{F}$ when the R-22 evaporator temperature is 41 psig $\left(20^{\circ} \mathrm{F}\right)$.

b. The methanol-solution-side pressure drop shall not exceed 4 psi at a flow rate of $20 \mathrm{gpm}$.

6. Shell and Tube Arrangement - General

a. All shell and tube vessels - desuperheater, both condensers, and evaporator (brine cooler) - shall be ASME construction: 300 psig refrigerant side and 125 psig on water or methanol side. The tube bundles shall be copper of not less than 0.035 -in. wall thickness.

b. Preferably, the shells shall be arranged in a vertical tier, stacked top to bottom in sequence of refrigerant flow.

c. The tiered shell stack should be located at the rear of the mechanical package assembly, in supports that permit easy removal of a single shell to be drawn out of the right end of the mechanical package (where removal space is available). 
7. Accumulator

a. The vendor shall submit alternate proposals for the accumulator with and without internal heat exchanger for liquid subcooling.

b. Proposal A - without subcooling

Under this propusal the accumulator shall be a shell of sufficient size to accept the entire refrigerant charge to protect the system from "liquid slop-over" onto the compressor. The internal suction pipe shall have an oil "lifter."

c. Proposal B - with subcooling

Under this proposal the accumulator shall be a shell-and-coil design, with the coil designed to subcool 226 psig highpressure liquid from an entering temperature of $110^{\circ} \mathrm{F}$ to a leaving temperature of $60^{\circ} \mathrm{F}$ at an evaporator temperature in the shell of $20^{\circ} \mathrm{F}$, with a shell of sufficient size to accept the entire refrigerant charge to protect the system from "liquid slop-over" onto the compressor. The internal suction pipe shall have an oil "lifter."

d. Under Prnposa 1 B, the vendor shall include manual sliutoff valves and a bypass to allow for test runs of the system both with and without liquid subcooling, so that ORNL can ascertain the relative cycle efficiency with subcooling.

8. Fan Coil Air Unit

a. The unit furnished will be one Carrier Model 42BH-1 horizontal draw-through air conditioner complete with 16-gage casing, 2 side access panels, 4-row conling coil with $1 / 2$-iri.-OD copper tube/aluminum plate fins tested for 350 psig with manual air vent, insulated drain pan, and discharge and 
return duct collars. The permanent flat filter will be removable from the side.

b. The unit is to be furnshed with Vee-belt drive for field mounting of motor. The Vee-belt drive will be sized so that the unit can deliver $800 \mathrm{cfm}$ at 1 in. total pressure.

c. The vendor shall furnish a separate, additional variable pitch motor sheave (for field adjustment).

\section{Fan Coil Motor}

a. The unit furnished will be one 1/3-hp, 1757-rpm 115-volt, single-phase, 60-cycle high-efficiency energy-saver fan motor as manufactured by Gould, Inc., Century Electric Motor Division, St. Louis, Missouri. 63166.

Figures B.2 through B.7, along with Fig. B.1, are the as-built drawings for the new mechanical package. Figures B. 8 and B. 9 are photographs of the unit. 


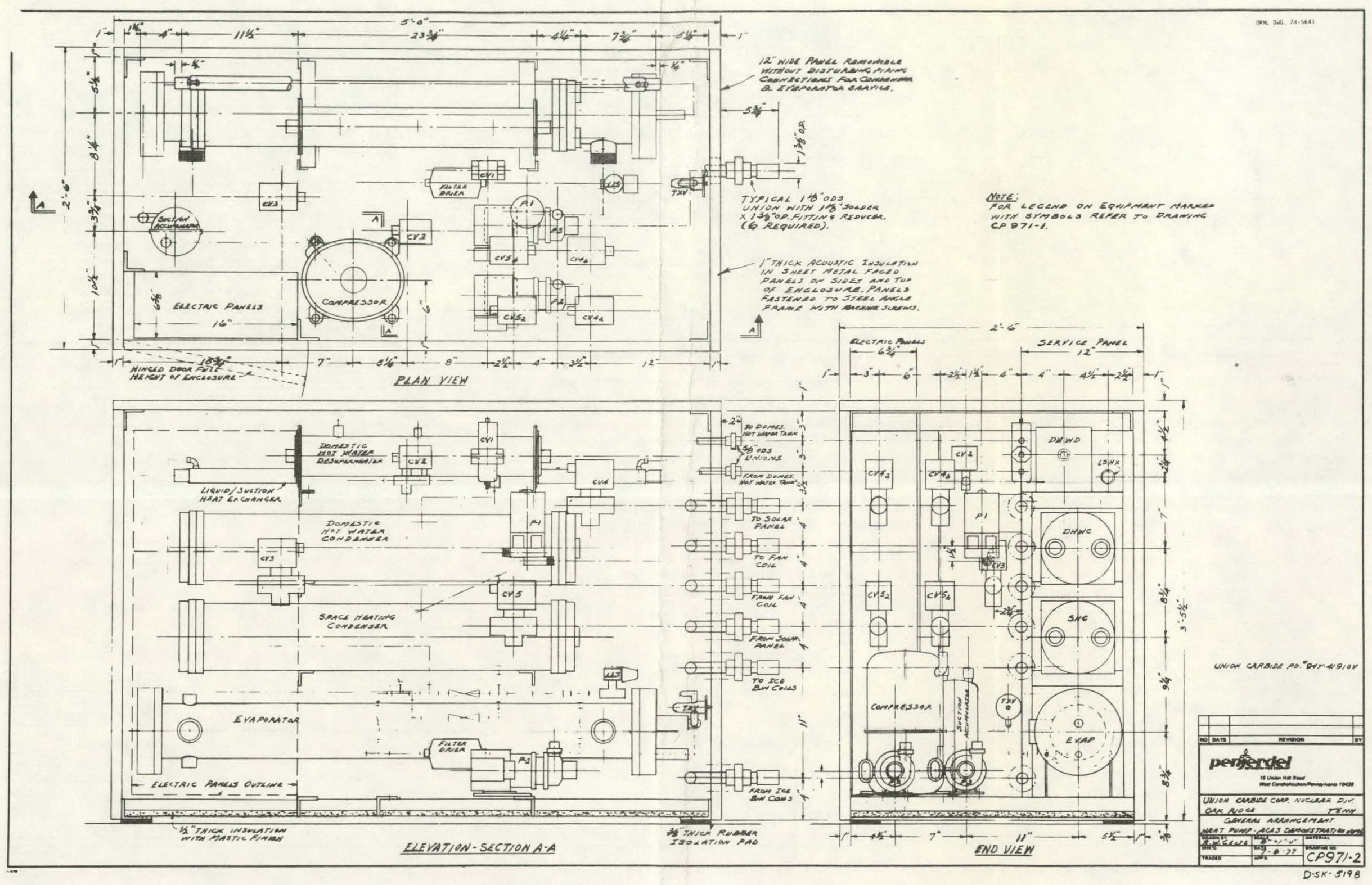

Fig. B.2. General arrangement. 


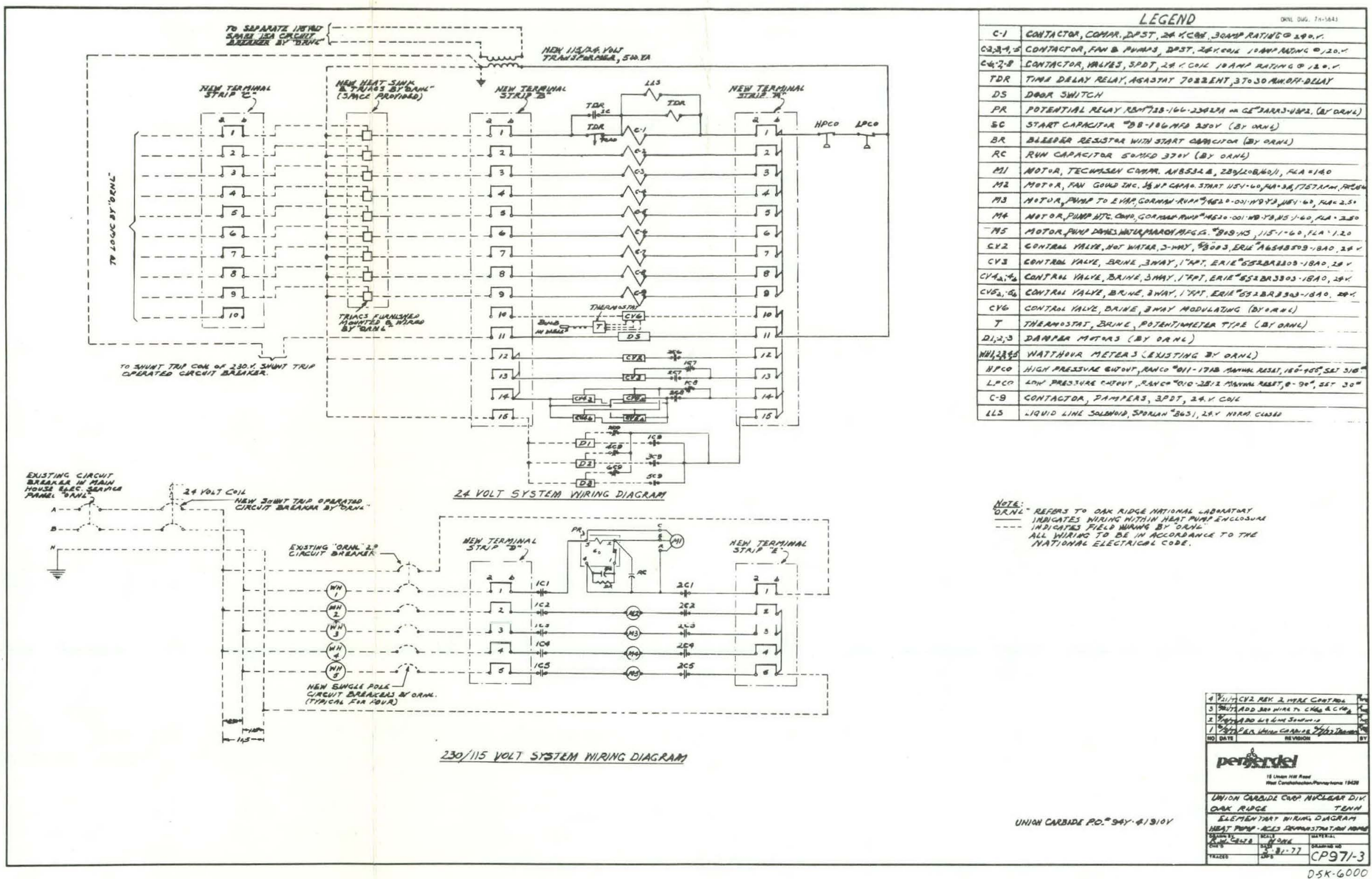

Fig. B.3. Elementary wiring diagram. 


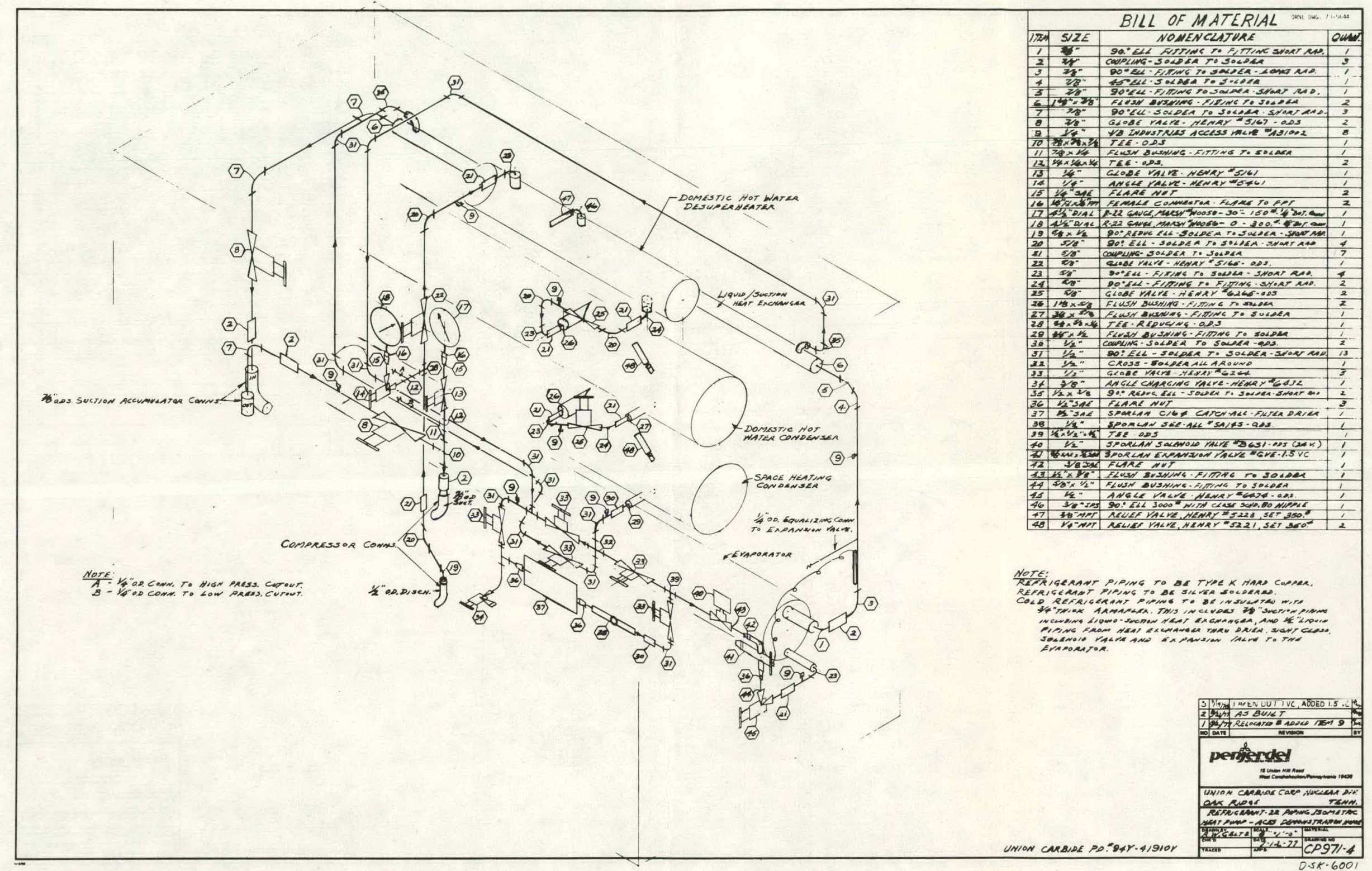

Fig. B.4. R-22 piping isometric. 


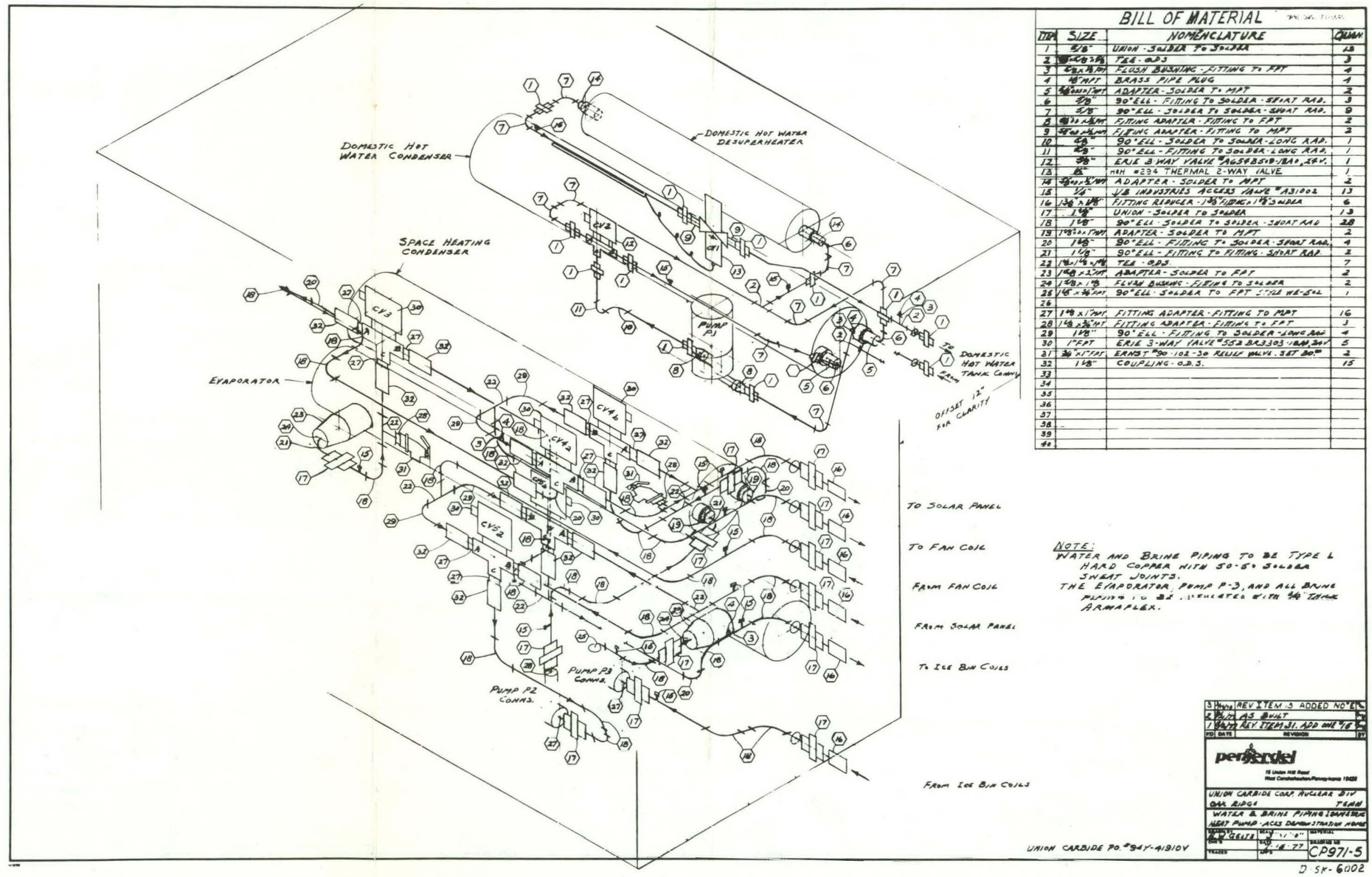

Fig. B.5. Water and brine piping isometric. 


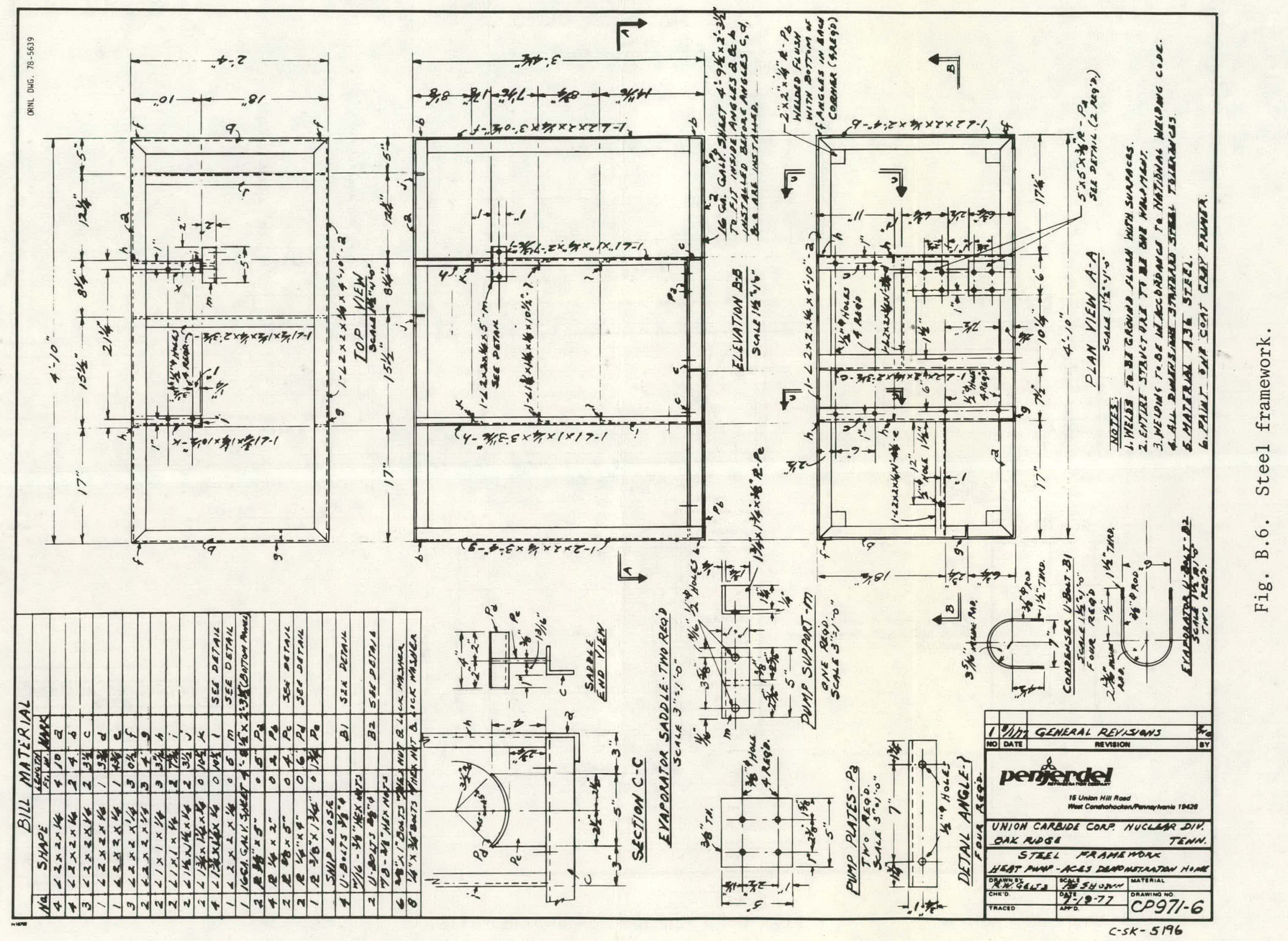




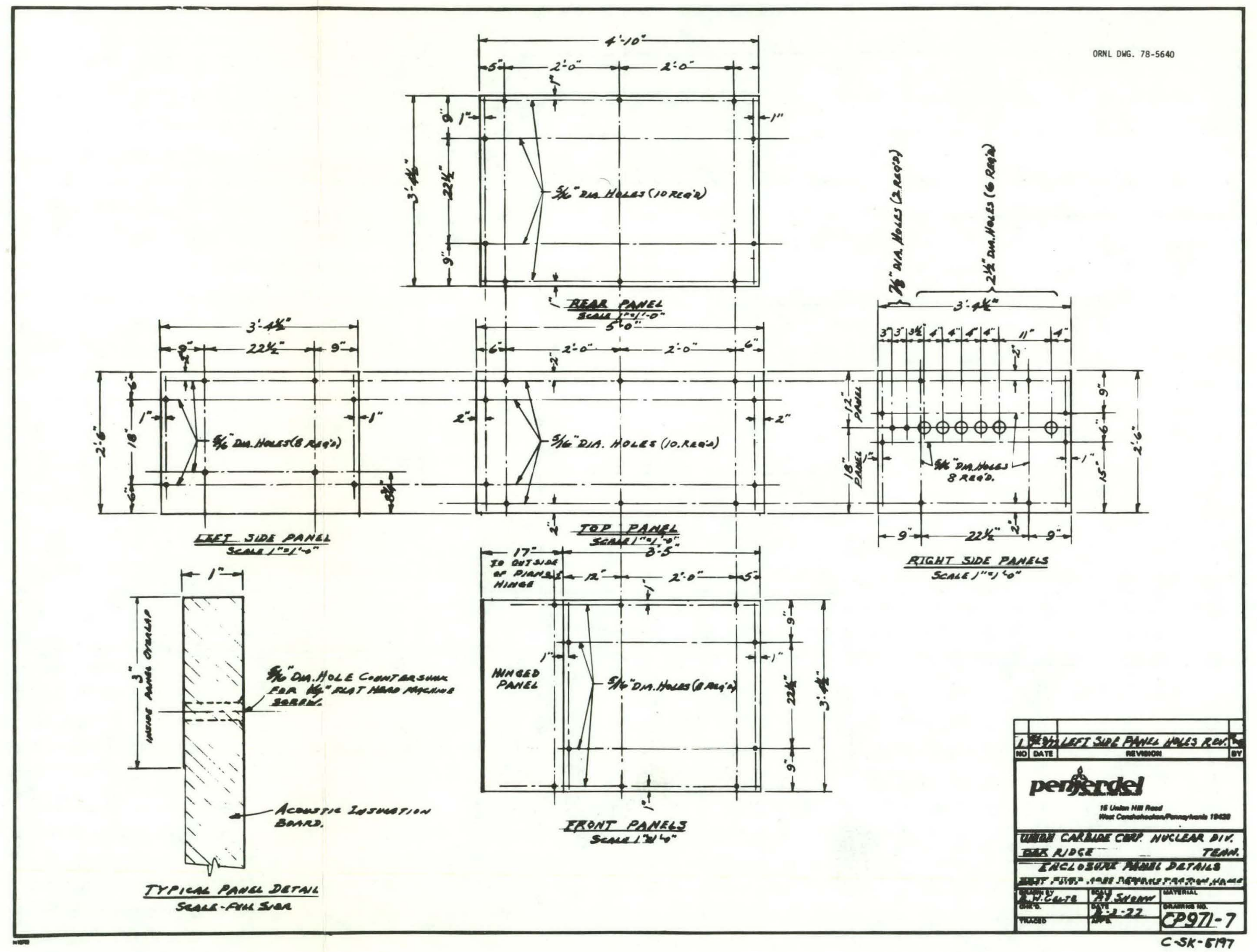

Fig. B.7. Enclosure panel details. 


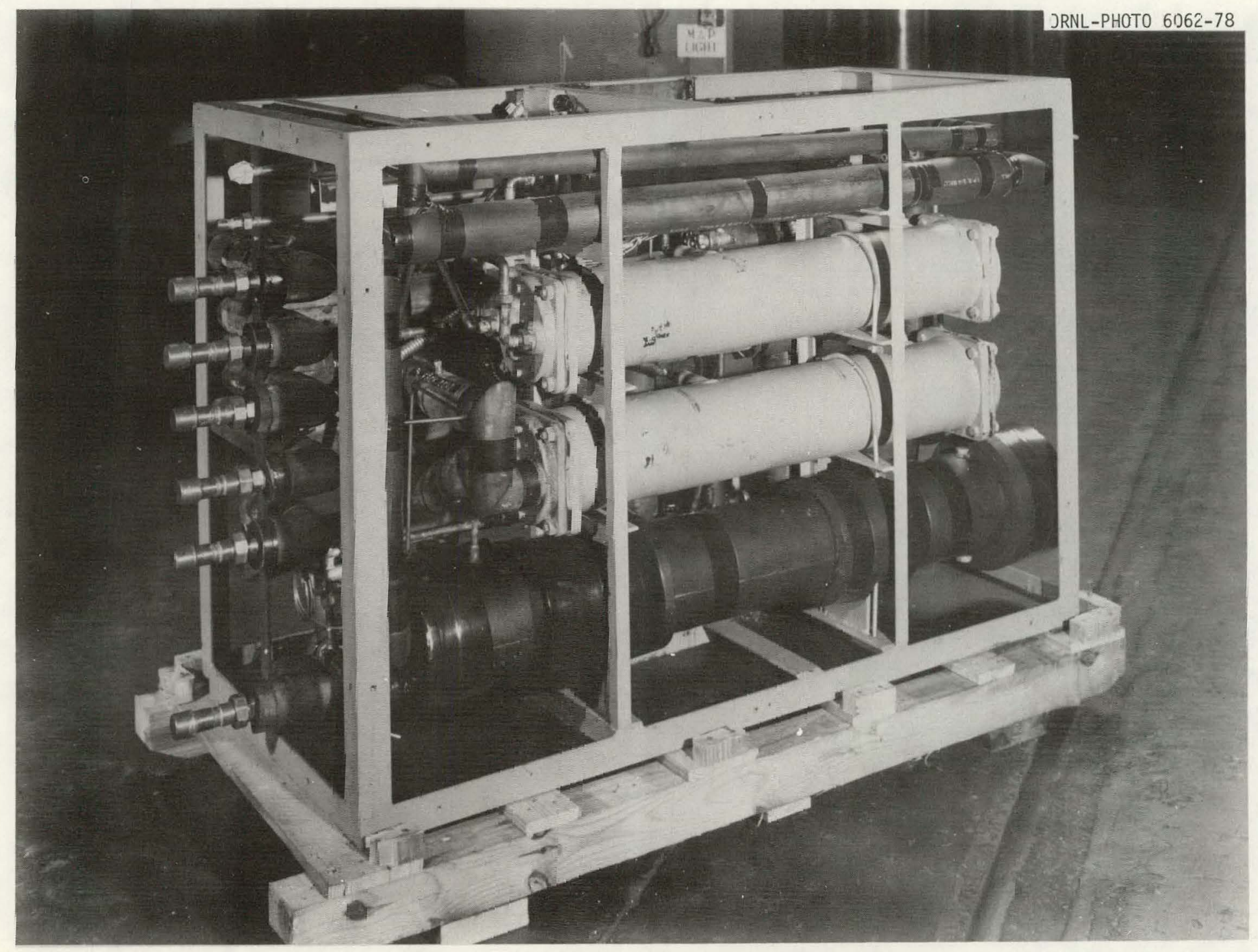

Fig. B.\&. New mechanical packıge. 


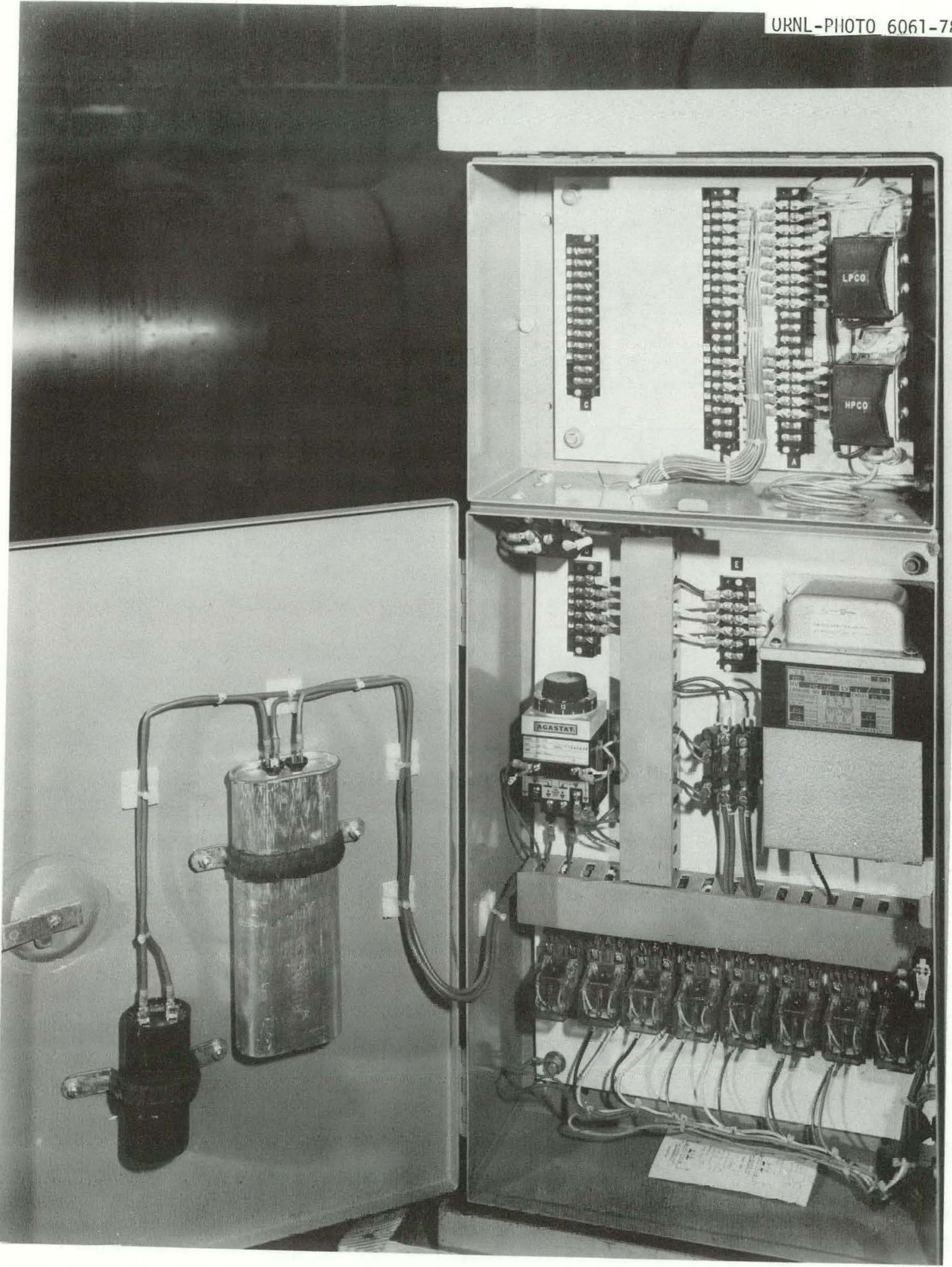

Fig. B.9. New mechanical package. 


\section{REFERENCES}

1. E. C. Hise, J. C. Moyers, and H. C. Fischer, Design Report for the ACES Demonstration House, ORNL/CON-1 (October 1976).

2. E. C. Hise, Performance Report for the ACES Demonstration House August 1976 through August 1977, ORNL/CON-19 (March 1978).

3. U. S. Department of Housing and Urban Development, Minimum Property Standards for One and Two Living Units, FHA No. 300, Rev. 512 (1971).

4. Owens-Corning Fiberglas Corporation, Energy Saving Homes - The Arkansas Story, Publication No. 4-BL-6958-D (August 1976).

5. J. R. Demonbrun, "Corrosion in Solar Energy Systems," presented at the Fifth Annual Energy Conference and Exhibition (WATTec), February 23, 1978.

6. A. A. Domingorena, Performance Evaluation of a Low-First-Cost, Three-Ton, Air-to-Air Heat Pump in the Heating Mode, ORNL/CON-18 (to be published). 
THIS PAGE

\section{WAS INTENTIONALLY LEFT BLANK}


ORNL/CON-26

INTERNAL DISTRIBUTTION

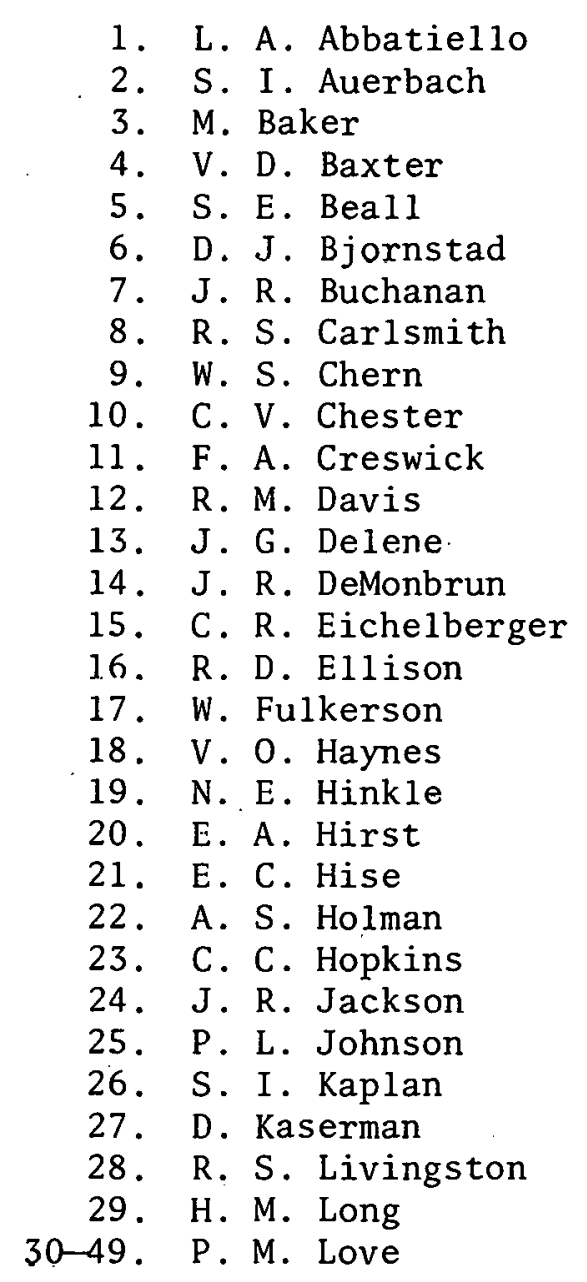

50. J. W. Michel

51. D. R. Miller

52. G. N. Miller

53-72. R. E. Minturn

73. W. R. Mixon

74. J. C. Moyers

75. E. A. Nephew

76. D. L. O'Neal

77. H. Postma

78. M. W. Rosenthal

79. T. H. Row

80. J. M. Schreyer

81. R. L. Spore

82. E. G. Struxness

83. T. Takayama

84. L. H. Thomas

85. D. B. Trauger

86. G. U. Ulrikson

87. D. J. Walukas

88. T. J. Wilbanks

89. G. R. Wilson

90. H. E. Zittel

91. A. Zucker

92. Biology Division Library

93-94. Centra1 Research Library

95-96. Energy Information Library

97. Document Reference Section

98. Laboratory Records - RC

99-101. Laboratory Records Department

102. ORNL Patent Office

\section{EXTERNAL DISTRIBUTION}

103. Mr. H. W. C. Aamot, Cold Regions Research and Engineering Laboratory, U.S. Army Corps of Engineers, P. O. Box 282, Hanover, $\mathrm{NH} 03755$

104. Mr. Roy W. Abbott, Manager, Advanced Technology, General Electric Company, Appliance Park, Building 6-208, Louisville, KY 40225

105. Mr. Ben Adams, President, Crouch and Adams, Inc., 106 Administration P rad, Oak Ridge, TN 37830

106. Ms. P. Bailey, Residential Specialist, Dow Chemical Company, 20 Perimeter Center East, Suite 2005, Atlanta, GA 30346

107. Mr. Arthur G. Baitz, Assistant Vice President and Director of. Planning, Robertshaw Controls Company, 1701 Byrd Avenue, P. 0. Box 26544, Richmond, VA 23261 
108. Mr. Hamp Barnett; Power Research Staff, Tennessee Valley Authority, 1310 Commerce Union Bank Building, Chattanooga, TN 37401

109. Dr. Thomas Bligh, Department of Mechanical Engineering, University of Minnesota, Minneapolis, MN 55455

110. Mr. Ed Bottum, President, Refrigeration Research, Inc., 525 North Fifth Street, Brighton, MI 48116

111. Mr. John H. Cable, Architectural and Engineering Systems Branch, Office of Conservation, Department of Energy, 20 Massachusetts Avenue NW, Washington, DC 20545

112. Dr. Louis-Marie Chounet, Batiment 200, Lab. de 1'Accelerateur Lineaire, 91405 Orsay, France

113. Mr. Irving Christensen, Consumer Plans Specialist, Northern Illinois Gas Company, P. 0. Box 190, Aurora, IL 60507

114. Mr. Bruce Doolittle, Marketing Manager, American Air Filter Company, 17570 West 12-Mile Road, Southfield, MI 48076

115. Mr. Gordon D. Duffy, Executive Editor, Air Conditioning News, 700 East Maple, Birmingham, MI 48011

116. Mr. William A. Elder, President, Automated Air Systems, Inc., 1723 Rhoadmiller Street, Richmond, VA 23220

117. Mr. Harry C. Fischer, P. O. Box 1687, Cocoa, FL 33932

118. Mr. Leo Foster, E11iott-Lewis Corporation, 2301 Cherry Street, Philadelphia, PA 19103

119. Mr. David Goldenberg, Energy Applications Staff, Systems and Energy Group of TRW Inc., One Space Park, Redondo Beach, CA 90278

120. Mr. Joe Gracia, Department of Energy, Oak Ridge Operations, Oak Ridge; TN 37830

121. Mr. Dieter Grether, Vice President, Engineering, Friedrich Air Conditioning and Refrigeration, P. 0. Box 1540, San Antonio, TX 78295

122. Mr. W. F. Hagon, President, Turbo Kefrigerating Company, 1515 Shady Oaks Drive, Expressway Industrial Park, P. 0. Bux 396, Denton, TX 76201

123. Dr. Richard M. Kelso, Associate Professor, School of Architecture, University of Tennessee, 100 Estabrook Hall, Knoxville, TN 37916

124. Mr. Jim Lcggoe, Philadelphia Electric Company, 2301 Market Street, Philadelphia, PA 19101

125. Mr. Herbert Lindah1, Manager, Advanced Engineering, Bohn Aluminum and Brass Corporation, Heat Transfer Division, 1625 East Voorhees Street, Danvil1e, IL 61832

126. Mr. John F. Lowry, Manager, Applications Department, Philadelphia Electric Company, 2301 Market Street, Philadelphia,. PA 19101

127. Mr. Calvin D. McCracken, President, Calmac Manufacturing Corporation, 150 South Van Brunt Street, Englewood, NJ 07631

128. Mr. Jim McCallum, Executive Editor, Air Conditioning and Refrigeration Business, 614 Superior Avenue West, Cleveland, $\mathrm{OH}_{\mathrm{H}}$ 44113

129. Mr. Jack McCormick, Research Engineer, Northern States Power Company, 414 Nicollet Ma11, Minneapolis, MN 55401

130. Mr. Ben Miller, Manager of Engineering, REMCOR Products Company, 321 East Grand Avenue, Chicago, IL 60611 
131. Mr. Dan Myers, Refrigeration Systems, 611 State Street, Newburg, IN 47630

132. Mr. Kenneth J. Nemeth, Executive Director, Southern States Energy Board, 7 Dunwoody Park, Suite 104, Atlanta, GA 30341

133. Mr. A. H. Rosenfeld, Lawrence Berkeley Laboratory, Building 50B, Room 5246, Berkeley, CA 94720

134. Dr. David P. Ross, Senior Scientist, Energy Resources and Conservation Division, Science Applications, Inc., 2028 Powers Ferry Road, Suite 260, Atlanta, GA 30339

135. Mr. Mike Shirkey, Plant Area Engineer, AC Spark Plugs, 1300 North Dort Highway, Department 25-55, Flint, MI 48556

136. Dr. Mason H. Somerville, Manager, Engineering Experiment Station, University of North Dakota, Grand Forks, ND 58202

137. Mr. Robert D. Vance, Zone Sales Manager, Carrier Air Conditioning Company, 735 North Cass Avenue, Westmont, IL 60559

138. Mr. Robert G. Werden, Werden \& Associates, Inc., P. 0. Box 414, Jenkintown, PA 19046

139. Institute of Energy Analysis, ORAU Library

140. Research and Technical Support Division, DOE-ORO

141-167. Technical Information Center, Department of Energy, P. 0. Box 62, Oak Ridge, TN 37830

168-600. External. Energy Conservation Distribution Mailing List and Energy Conservation Office (9102-1, Room 2) 